\title{
Photolytic mechanisms of hydroxylamine $\uparrow$
}

Cite this: RSC Adv., 2020, 10, 8319

\author{
Jittima Thisuwan, ${ }^{a}$ Phorntep Promma ${ }^{\mathrm{b}}$ and Kritsana Sagarik (D) *b
}

The photodissociation of small molecules has been extensively studied because of the increase in environmental problems related to the atmosphere of the Earth. In this work, the photodissociation mechanisms of hydroxylamine $\left(\mathrm{NH}_{2} \mathrm{OH}\right)$ as a model molecule in its lowest singlet-excited $\left(\mathrm{S}_{1}\right)$ state were systematically studied using the complete active space second-order perturbation theory (CASPT2) and transition state theory (TST). In particular, this study focused on nonradiative relaxation processes that convert the $\mathrm{S}_{0} \rightarrow \mathrm{S}_{1}$ excited-state molecule to its products in their respective electronic ground states. The potential energy curves obtained from relaxed scans suggest that $\mathrm{O}-\mathrm{H}$ dissociation is the preferred process in the $\mathrm{S}_{1}$ state. For the $\mathrm{N}-\mathrm{O}$ and $\mathrm{N}-\mathrm{H}$ dissociation pathways, thermally excited precursors were hypothesized to form in the $\mathrm{S}_{0}$ state to circumvent $\mathrm{O}-\mathrm{H}$ dissociation. Thus, $\mathrm{S}_{0} \rightarrow \mathrm{S}_{1}$ vertical excitations lead to transition structures in the $S_{1}$ state, which fragment to their respective electronic-ground-state products. The thermodynamic and kinetic results confirmed the precursor hypothesis, showing that the exothermic energy caused by the formation of $\mathrm{HNO}$ and $\mathrm{H}_{2}$ is sufficient to generate such precursors in the $\mathrm{S}_{0}$ state. Additionally, the TST confirmed that unimolecular isomerization-dissociation is a two-step process that generates products effectively by direct photolysis of the corresponding covalent bonds. In particular, the process consists of $\mathrm{O}-\mathrm{H}$ bond dissociation, followed by spontaneous isomerization and formation of $\mathrm{H}_{2}$ in its electronic ground state, resulting in the high quantum yield observed in the UV absorption experiments in the preferential formation of $\mathrm{HNO}$ and $\mathrm{H}_{2}$. The configuration interaction coefficients of the characteristic structures on the potential energy curves revealed considerable changes in the multiconfigurational character of the wavefunctions, especially for the transition structures. These are characterized by the development of Rydberg orbitals, being produced at the intersection of the $S_{0}$ and $S_{1}$ states. The present study highlights the effects of thermal selectivity and the multiconfigurational character of the wavefunctions on photodissociation. Because detailed information on the photolytic mechanisms of isolated $\mathrm{NH}_{2} \mathrm{OH}$ is limited both theoretically and experimentally, these results provide fundamental insight into unimolecular photodissociation, posing ground for future studies on related systems.

Received 27th December 2019 Accepted 19th February 2020

DOI: 10.1039/c9ra10956k

rsc.li/rsc-advances covalent bonds, ${ }^{3}$ which can generate the nitroxyl $\left(\mathrm{NH}_{2} \mathrm{O}\right)$, hydroxylamino $(\mathrm{NHOH})$, amino $\left(\mathrm{NH}_{2}\right)$, hydroxyl $(\mathrm{OH})$ radical groups, and hydrogen (H); (ii) intramolecular isomerization/ dissociation, which can produce, e.g., nitrosyl hydride $(\mathrm{HNO})^{\mathbf{8 - 1 0}}$ and ammonia oxide $\left(\mathrm{NH}_{3} \mathrm{O}\right) \cdot{ }^{11-14}$

In the direct photolysis pathway, ultraviolet (UV) absorption experiments have shown that the $\mathrm{H}$-atom channel, in which two $\mathrm{H}$ atoms are generated with a quantum efficiency greater than one (1.7), is the preferred process at an absorption wavelength of $193 \mathrm{~nm}$. In this pathway, $\mathrm{N}-\mathrm{O}$ dissociation is a minor process, with a quantum efficiency of less than $0.1 .^{5}$ Instead, photolysis by UV absorption at $240 \mathrm{~nm}$ leads mainly to the dissociation of $\mathrm{N}-\mathrm{O}$ and formation of $\mathrm{NH}_{2}$ and $\mathrm{OH}$ in their electronic ground states. ${ }^{7}$ Thus, though the $\mathrm{O}-\mathrm{H}$ dissociation was first proposed, both $\mathrm{O}-\mathrm{H}$ and $\mathrm{N}-\mathrm{O}$ dissociation have been reported as primary processes (representing $60 \%$ and $40 \%$, respectively) in the direct photolysis of $\mathrm{NH}_{2} \mathrm{OH}$ vapor at $298 \mathrm{~K}$, because of the possible thermal decomposition. ${ }^{3}$
${ }^{a}$ Division of Science, Faculty of Education, Nakhon Phanom University, Nakhon Phanom 48000, Thailand

${ }^{b}$ School of Chemistry, Institute of Science, Suranaree University of Technology, Nakhon Ratchasima 30000, Thailand. E-mail: kritsana@sut.ac.th; Fax: +66 44 224635; Tel: +6644224635

$\dagger$ Electronic supplementary information (ESI) available. See DOI: 10.1039/c9ra10956k 


\section{Direct covalent bond dissociations}
(1) $\mathrm{NH}_{2} \mathrm{OH}$

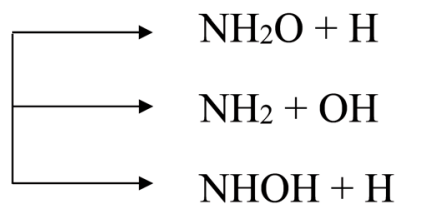
$193 \mathrm{~nm}(6.42 \mathrm{eV} ; 620 \mathrm{~kJ} / \mathrm{mol})^{a}$
$463 \mathrm{~nm}(2.68 \mathrm{eV} ; 258 \mathrm{~kJ} / \mathrm{mol})^{b}$
$297 \mathrm{~nm}(4.17 \mathrm{eV} ; 402 \mathrm{~kJ} / \mathrm{mol})^{\mathrm{c}}$

\section{(cis and trans $\mathrm{H}$ atoms, respectively)}

\section{Unimolecular isomerization dissociations}
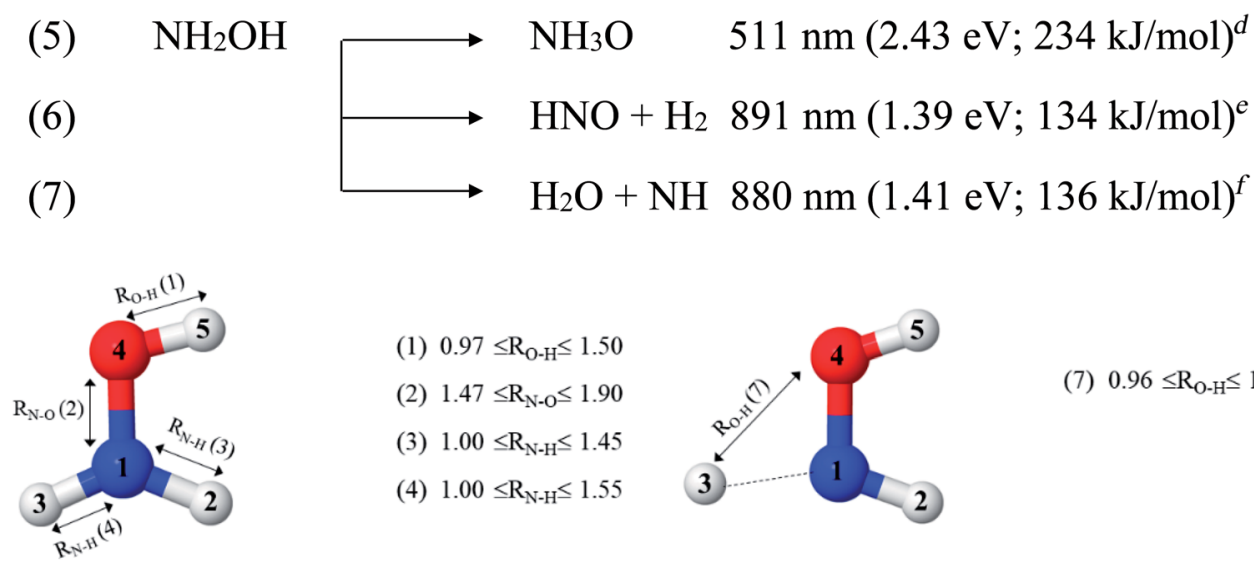

(1) $0.97 \leq \mathrm{R}_{\mathrm{O}-\mathrm{H}} \leq 1.50$

(2) $1.47 \leq \mathrm{R}_{\mathrm{N}-\mathrm{O}} \leq 1.90$

(3) $1.00 \leq \mathrm{R}_{\mathrm{N}-\mathrm{H}} \leq 1.45$

(4) $1.00 \leq \mathrm{R}_{\mathrm{N}-\mathrm{H}} \leq 1.55$

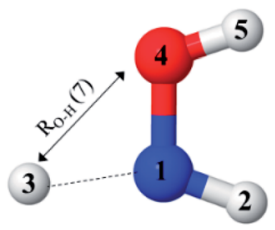

(7) $0.96 \leq \mathrm{R}_{\mathrm{O}-\mathrm{H}} \leq 1.80$

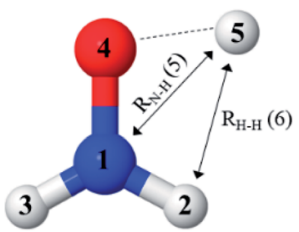

(5) $0.98 \leq \mathrm{R}_{\mathrm{N}-\mathrm{H}} \leq 1.85$

(6) $0.73 \leq \mathrm{R}_{\mathrm{H}-\mathrm{H}} \leq 1.50$

Fig. 1 Direct covalent bond dissociations and unimolecular-isomerization dissociations for $\mathrm{NH}_{2} \mathrm{OH}$ in the gas phase suggested based on experiments and theories. Double sided arrows represent the degrees of freedom used in the calculations of the potential energy curves. Distances are in $\AA$. (...) = dissociation channel. ${ }^{a} U V$ absorption in ref. $5 ;{ }^{b}$ the value reported in Table II of ref. 7 based on the analysis of the data in ref. 41; ${ }^{c}$ threshold energy for the photodissociation of $\mathrm{NH}_{3}$ into $\mathrm{NH}$ and $\mathrm{H}_{2}$ from photoemission in ref. $42 ;{ }^{d}$ ab initio calculations in the electronic

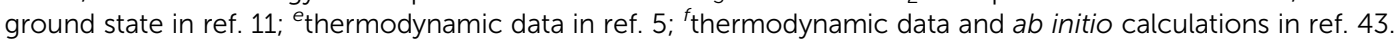

Analysis of the $\mathrm{H}$-atom Doppler profiles ${ }^{5}$ suggested that the only energetically accessible path to generate two $\mathrm{H}$ atoms is

$$
\mathrm{NH}_{2} \mathrm{OH}+h \nu \rightarrow \mathrm{H}+\mathrm{HNO}+\mathrm{H}
$$

and that the two $\mathrm{H}$ atoms are produced in two stepwise-decay processes, which are

$$
\mathrm{NH}_{2} \mathrm{OH}+h \nu \rightarrow \mathrm{H}+\mathrm{NH}_{2} \mathrm{O} \rightarrow \mathrm{H}+\mathrm{HNO}+\mathrm{H}
$$

and

$$
\mathrm{NH}_{2} \mathrm{OH}+h \nu \rightarrow \mathrm{H}+\mathrm{NHOH} \rightarrow \mathrm{H}+\mathrm{HNO}+\mathrm{H} .
$$

Although the final products of eqn (2) and (3) are identical, the intermediates are different. Therefore, it is necessary to determine which covalent bond, $\mathrm{O}-\mathrm{H}$ or $\mathrm{N}-\mathrm{H}$, dissociates first.
Limited evidence suggests that the $\mathrm{N}-\mathrm{H}$ dissociation of eqn (3) occurs first. $^{5}$

To study the photodissociation of $\mathrm{NH}_{2} \mathrm{OH}$, ab initio calculations have been previously performed on low-lying singlet states using the complete active space self-consistent field (CASSCF) method. ${ }^{7}$ The potential energy curves obtained from the freezescan method, in which the remaining coordinates were fixed at their MP2/6-31G** equilibrium values in the electronic ground state, showed that excitations from the two lowest-lying singlet states $\left(n_{\text {orb }}=8\right.$ and 9) are possible and can lead to fragmentations through the $\mathrm{H}$-atom, $\mathrm{NH}_{2}$, and $\mathrm{OH}$ channels. It was concluded that these two dissociation processes result from excitations with different wavelengths rather than different excitation mechanisms. ${ }^{7}$ This is consistent with other ab initio calculations based on the coupled electron pair approximation, which showed that the two highest occupied orbitals, $2 \mathrm{a}^{\prime \prime}$ and 
$7 \mathrm{a}^{\prime}$, are associated with the $2 \mathrm{p}$ lone-pair orbitals of the $\mathrm{O}$ and $\mathrm{N}$ atoms, respectively, with an energy difference of less than $1 \mathrm{eV} .^{15}$

The end product of $\mathrm{NH}_{2} \mathrm{OH}$ photolysis at $193 \mathrm{~nm}(6.42 \mathrm{eV})^{5}$ is $\mathrm{HNO}$, which is an important intermediate in the formation of NO by combustion ${ }^{16}$ and by the catalytic decomposition of ozone $\left(\mathrm{O}_{3}\right)$ in the stratosphere and reaction with $\mathrm{HNOH} .{ }^{17} \mathrm{HNO}$ is a reactive radical with a rather long lifetime $(0.1 \mathrm{~s}),{ }^{\mathbf{1 8}}$ and it has been studied extensively both experimentally and theoretically. ${ }^{8}$ Although computational studies have suggested the formation of triplet $\mathrm{HNO}\left({ }^{3} \mathrm{HNO}\right)$, the bent structure in the singlet state $\left({ }^{1} \mathrm{HNO}\right)$ was concluded to be the most stable, ${ }^{19}$ with a singlet-triplet energy gap of $77 \mathrm{~kJ} \mathrm{~mol}^{-1} .^{20}$ Using thermodynamic data, the threshold wavelength $\left(\lambda_{\text {thres }}\right)$ for the formation of $\mathrm{HNO}$ and $\mathrm{H}_{2}$ after excitation of $\mathrm{NH}_{2} \mathrm{OH}$ by $193 \mathrm{~nm}$-UV radiation was predicted to be $891 \mathrm{~nm}(1.39 \mathrm{eV}) .^{5}$

The interconversion between $\mathrm{NH}_{2} \mathrm{OH}$ and $\mathrm{NH}_{3} \mathrm{O}$ is a prototypical model for unimolecular chemical transformations (i.e., isomerization). ${ }^{11}$ Although the energy barrier associated with intramolecular hydrogen/proton transfer from the $\mathrm{O}$ atom to $\mathrm{N}$ is rather high in the electronic ground state of this system $\left(\sim 234 \mathrm{~kJ} \mathrm{~mol}^{-1}\right),{ }^{\mathbf{1 1}}$ mass spectroscopic experiments and ab initio calculations confirmed the existence of neutral $\mathrm{NH}_{3} \mathrm{O}$ in the gas phase, ${ }^{12}$ and structure-reactivity analysis of the equilibrium constants suggested that $\sim 20 \%$ of aqueous $\mathrm{NH}_{2} \mathrm{OH}$ solution is composed by $\mathrm{NH}_{3} \mathrm{O} .{ }^{13}$

In this work, the photolytic mechanisms of a single $\mathrm{NH}_{2} \mathrm{OH}$ molecule in the lowest singlet-excited $\left(\mathrm{S}_{1}\right)$ state were studied using $a b$ initio calculations through the complete active space second-order perturbation theory (CASPT2) with the aug-ccpVDZ basis set. Different from previous ones, this study focuses on nonradiative relaxation processes that convert the excited-state molecule to its electronic-ground-state products and on the effects of thermal energy on photodissociation. The structures and energetics of the precursors, and the transition structures of the seven dissociation channels, shown in Fig. 1, were studied in detail using the $S_{0}$ and $S_{1}$ potential energy curves obtained from CASPT2 and relaxed scans. To determine the contributions of the different electronic states to photodissociation, we analyzed the configuration interaction (CI) coefficients corresponding to the multiconfigurational character of each structure on the potential energy curves. Because of the limited theoretical and experimental information, the role of thermal energy in the photolytic mechanisms was discussed using the transition state theory (TST), ${ }^{21,22}$ considering the 200-1200 K temperature range.

\section{Computational methods}

\section{$A b$ initio calculations}

Because the photodissociation of $\mathrm{NH}_{2} \mathrm{OH}$ involves fragmentation and formation of covalent bonds, closed- and open-shell configurations must be considered..$^{23}$ To account for the multiconfigurational character of $\mathrm{NH}_{2} \mathrm{OH}$ photolysis, $a b$ initio calculations were performed using CASPT2, which is a widely recognized method for excited-state calculations. ${ }^{24}$ It should be mentioned that although the multistate complete-active-space second-order perturbation (MS-CASPT2) method is more accurate, MS-CASPT2 calculations are computer intensive and therefore applicable only to small systems. In this work, because the energy gradients with respect to degrees of freedom and Hessian had to be computed extensively, the CASPT2 method was employed to optimize the computational resources.

The electronic ground state of $\mathrm{NH}_{2} \mathrm{OH}$ in its equilibrium structure with $C_{\mathrm{s}}$ symmetry is represented by $\left(1 a^{\prime}\right)^{2}\left(2 a^{\prime}\right)^{2}\left(3 a^{\prime}\right)^{2}\left(4 a^{\prime}\right)^{2}\left(1 a^{\prime \prime}\right)^{2}\left(5 a^{\prime}\right)^{2}\left(6 a^{\prime}\right)^{2}\left(2 a^{\prime \prime}\right)^{2}\left(7 a^{\prime}\right)^{2}$. The active space was defined by assigning ten electrons $(n=10)$ to nine active orbitals $(m=9)$, and hereafter abbreviated as the $(10,9)$ active space. The remaining electrons were assigned to four doubly occupied orbitals (close $=4$ ). For $\mathrm{NH}_{2} \mathrm{OH}$, CASPT2 $(10,9)$ calculations involved 5292 CASSCF reference wavefunctions. The aug-cc-pVDZ basis set was satisfactorily used to optimize computational resources. Indeed, augmented basis sets with diffuse functions are reportedly suitable for singlet-state calculations, ${ }^{24}$ and in our previous study, CASPT2/aug-cc-pVDZ calculations were shown to yield reasonable potential energy curves and $\mathrm{S}_{0} \rightarrow \mathrm{S}_{1}$ vertical excitation energies for water clusters. $^{25}$

The $a b$ initio CI calculations in the CASSCF framework ${ }^{7}$ revealed that the first two electronic excited states involve excitations of a single electron from the two highest occupied orbitals, $2 \mathrm{a}^{\prime \prime}\left(n_{\text {orb }}=8\right)$ and $7 \mathrm{a}^{\prime}\left(n_{\text {orb }}=9\right)$ ), to the two lowest unoccupied ones, $8 \mathrm{a}^{\prime}\left(n_{\text {orb }}=10\right)$ and $9 \mathrm{a}^{\prime}\left(n_{\text {orb }}=11\right)$, and that these low-lying excited states possess Rydberg and dissociativevalence character, which results from adiabatic excitation. ${ }^{26}$ Because of this, the $S_{1}$ state was calculated adiabatically. Schematic diagram showing doubly occupied and active spaces used in CASPT2 $(10,9)$ calculations and spatial distributions of the orbitals potentially involved in the $\mathrm{S}_{0} \rightarrow \mathrm{S}_{1}$ excitation of $\mathrm{NH}_{2} \mathrm{OH}$ are illustrated in Fig. S1. $\dagger$

Additionally, because previous $a b$ initio calculations suggested that the products of photodissociation forming at conical intersections do not necessarily have $C_{\mathrm{s}}$ symmetry, ${ }^{\mathbf{2 6}}$ and because nonradiative relaxations of the excited structures are our primary interest, the CASPT2 $(10,9)$ geometry was optimized with no geometrical constraints ( $C_{1}$ symmetry). To study the effects of the multiconfigurational wavefunctions in the photolysis of $\mathrm{NH}_{2} \mathrm{OH}$, the CI coefficients of the equilibrium, transition, and final structures on the potential energy curves were examined. The CASPT2(10,9) calculations were performed using the MOLPRO software package $\mathrm{e}^{27,28}$ and applying the Werner-Meyer-Knowles nonlinear method in the orbital/state optimization. ${ }^{29-31}$

\section{Potential energy curves and equilibrium structures}

To obtain information on the equilibrium structures and elementary photodissociation steps, the potential energy curves of the direct $\mathrm{O}-\mathrm{H}, \mathrm{N}-\mathrm{O}$, and $\mathrm{N}-\mathrm{H}$ dissociations were constructed as relaxed scans in the $S_{1}$ state. Here, the structural parameters of the potential energy curves were optimized using the CASPT2 $(10,9)$ and quadratic steepest descent (QSD) methods, ${ }^{32}$ and the same geometries were used to calculate the energies of 
the $S_{0}$ potential energy curves. All degrees of freedom used in these $a b$ initio calculations are included in Fig. 1.

Because our preliminary CASPT2 $(10,9)$ results showed that the $\mathrm{O}-\mathrm{H}$ dissociation of channel (1) occurs preferentially along a purely repulsive potential energy curve in the $S_{1}$ state, the $S_{1}$ potential energy curves for the $\mathrm{N}-\mathrm{O}$ and $\mathrm{N}-\mathrm{H}$ dissociation of channels (2)-(4) were constructed by constraining the $\mathrm{O}-\mathrm{H}(5)$ distance at the equilibrium value of the ground $\left(\mathrm{S}_{0}\right)$ state $\left(R_{\mathrm{O}-}\right.$ $\mathrm{H}(5)=0.97 \AA)$. These calculated potential energy curves were used to characterize the potential precursors in their electronic ground state outside the Franck-Condon region of the equilibrium structure. From these, the $S_{0} \rightarrow S_{1}$ vertical excitations could provide the transition and final structures in their respective ground state.

Because mass spectroscopy measurements confirmed the existence of neutral $\mathrm{NH}_{3} \mathrm{O}$ in the gas phase, ${ }^{\mathbf{1 2}}$ and because intramolecular isomerization is one of the most common radical reactions in electronic excited states, the unimolecular isomerization potential energy curve ${ }^{\mathbf{1 1}}$ for the formation of ammonia oxide $\left(\mathrm{NH}_{2} \mathrm{OH} \rightarrow \mathrm{NH}_{3} \mathrm{O}\right)$ of channel (5) was constructed in the $\mathrm{S}_{1}$ state by transferring the dissociated $\mathrm{H}(5)$ atom of channel (1) to the $\mathrm{N}$ atom (Fig. 1). Similarly, because HNO and $\mathrm{H}_{2}$ are the dominant products of photolysis at the lowest absorption wavelength $(193 \mathrm{~nm}){ }^{5}$ and because $\mathrm{O}-\mathrm{H}$ dissociation is the primary process, an intramolecular isomerization that generates $\mathrm{HNO}$ and $\mathrm{H}_{2}$ (channel (6)) was assumed by transferring the dissociated $\mathrm{H}$ atom of channel $(1)(\mathrm{H}(5))$ to one of the $\mathrm{H}$ atoms $(\mathrm{H}(2)$ or $\mathrm{H}(3))$ of the $\mathrm{NH}_{2}$ group (Fig. 1). A high energy barrier caused by intramolecular rearrangement was assumed for the $\mathrm{H}_{2}$ generation mechanisms. ${ }^{7}$

Although $\mathrm{NH}$ was not detected during UV photolysis at $193 \mathrm{~nm},{ }^{7}$ it is interesting to calculate the transition structures and energetics of the $\mathrm{H}(2) \rightarrow \mathrm{O}$ and $\mathrm{H}(3) \rightarrow \mathrm{O}$ isomerization of channel (7) and compare them with those of the $\mathrm{H}(5) \rightarrow \mathrm{N}$ isomerization of channel (5). Similar to the approach used for $\mathrm{N}-\mathrm{O}$ and $\mathrm{N}-\mathrm{H}$ dissociation, the unimolecular isomerizationdissociation process that underlies the formation of $\mathrm{NH}$ and $\mathrm{H}_{2} \mathrm{O}$ was simulated by constraining the $\mathrm{O}-\mathrm{H}(5)$ distance at 0.97 $\AA$ and transferring the dissociated $\mathrm{H}$ atom of channel (3) or (4) $(\mathrm{H}(2)$ or $\mathrm{H}(3))$ to the $\mathrm{O}$ atom.

\section{The effects of thermal energy on photodissociation}

Because the potential energy curves obtained by CASPT2 $(10,9)$ calculations represent the reaction paths at $0 \mathrm{~K}$, the effects of temperature must be incorporated in the model. The mechanisms represented in Fig. 1 involve covalent bond dissociation and isomerization of a single molecule. Therefore, unimolecular rate constants $(k)$ were used, calculating them in the 200-1200 K temperature range according to TST, ${ }^{21,22}$ which can be applied when the energy barrier is higher than the thermal energy $\left(k_{\mathrm{B}} T\right){ }^{33}$ Although some of the direct covalent bond dissociations involve transferring the $\mathrm{H}$ atom, the $\mathrm{S}_{0}$ and $\mathrm{S}_{1}$ potential energy curves evidenced that the $S_{0}$ state has a broad energy barrier, whereas $S_{1}$ is barrierless, implying that quantum mechanical tunneling has no significant role. Therefore, the classical $\left(k^{\text {Class }}\right)$ and quantized-vibrational $\left(k^{\mathrm{Q}-\mathrm{vib}}\right.$, which includes the zero-point vibrational energies) rate constants were initially computed. For the one-dimensional energy profile, the classical transition rate constant is expressed $a^{34}$

$$
k^{\text {Class }}(T)=\frac{k_{\mathrm{B}} T}{h} \frac{Q^{\neq}}{Q^{\mathrm{R}}} \mathrm{e}^{-\Delta E^{\neq} / k_{\mathrm{B}} T},
$$

where $Q^{\neq}$and $Q^{\mathrm{R}}$ are the partition functions of the transition and reactant structures, respectively, and $\Delta E^{\neq}$is the potential energy barrier obtained from the relaxed-scan potential energy curve. $k_{\mathrm{B}}$ and $h$ are the Boltzmann and Planck constants, respectively.

To calculate the rate constant with quantized vibrations, the barrier height obtained with the zero-point vibrational energy $\left(\Delta E_{\mathrm{ZPE}}^{\neq}\right)$is used, and the partition functions are calculated in the harmonic oscillator approximation:

$$
k^{\mathrm{Q}-\mathrm{vib}}(T)=\frac{k_{\mathrm{B}} T}{h} \frac{Q_{\mathrm{ZPE}}^{\neq}}{Q_{\mathrm{ZPE}}^{\mathrm{R}}} \mathrm{e}^{-\Delta E_{\mathrm{ZPE}}^{\neq} / k_{\mathrm{B}} T} .
$$

Here, $Q_{\mathrm{ZPE}}^{\neq}$and $Q_{\mathrm{ZPE}}^{\mathrm{R}}$ are the partition functions of the transition and reactant structures obtained with respect to their zero-point vibrational energies. Additionally, the crossover temperature $\left(T_{\mathrm{c}}\right)$, i.e., the temperature below which the transition states are dominated by quantum mechanical tunneling, was computed as $^{35,36}$

$$
T_{\mathrm{c}}=\frac{h \Omega^{\neq}}{2 \pi k_{\mathrm{B}}},
$$

where $\Omega^{\neq}$is the imaginary frequency of the transition structure. Although the effects of thermal energy are discussed only for the highest temperature $(1200 \mathrm{~K})$, i.e., the temperature at which high energy precursors could be populated, the rate constants with quantized vibrations and second-order Wigner correction $\left(k^{\mathrm{S}-\mathrm{Wig}}\right)^{35,36}$ were calculated to verify the insignificance of quantum mechanical tunneling. Assuming that tunneling occurs at the top of the barrier, the Wigner correction to the rate constant is

$$
\kappa^{\mathrm{S}-\mathrm{Wig}}(T)=1+\frac{1}{24}\left(\frac{h \Omega^{\neq}}{k_{\mathrm{B}} T}\right)^{2},
$$

where $\kappa^{\mathrm{S}-\mathrm{Wig}}$ is the Wigner transmission coefficient, which is 1 in the classical limit $(h=0)$. Then, the Wigner corrected rate constant is

$$
k^{\mathrm{S}-\mathrm{Wig}}(T)=\kappa^{\mathrm{S}-\mathrm{Wig}}(T) k^{\mathrm{Q}-\mathrm{vib}}(T) .
$$

Finally, the enthalpy changes $(\Delta H)$ in the elementary reactions were computed. For the reactions with energy barrier higher than $k_{\mathrm{B}} T$, the linear relationship between $\ln k^{\mathrm{Q} \text {-vib }}(T)$ and $1 / T$ was used to calculate the activation enthalpy $\left(\Delta H^{\neq}\right)$through the Eyring equation, ${ }^{34}$

$$
\ln k^{\mathrm{Q}-\mathrm{vib}}(T)=\ln A-\frac{\Delta H^{\neq}}{R T}+\frac{\Delta S^{\neq}}{R},
$$

where $\Delta S^{\neq}$is the activation entropy, and $R$ is the gas constant. In these cases, $\Delta H^{\neq}$was extracted from the slope of the plot. For the elementary reactions with energy barrier lower than $k_{\mathrm{B}} T$ (or barrierless), the conventional expression for the relative Gibbs free energy $\left(\Delta G^{\mathrm{Rel}}=\Delta H^{\mathrm{Rel}}-T \Delta S^{\mathrm{Rel}}\right)$ was used to approximate 
the exothermic enthalpy ( $\left.\Delta H^{\mathrm{Rel}}\right)$ as the $y$-intercept of the linear regression of $\Delta G^{\mathrm{Rel}}$ as a function of $T$.

The results confirmed that, for direct covalent bond dissociation at $1200 \mathrm{~K}, k^{\mathrm{S}-\mathrm{Wig}}$ is at most $8 \%$ higher than $k^{\mathrm{Q}-\mathrm{vib}}$, confirming the applicability of $k^{\mathrm{Q}-\mathrm{vib}}$ to this system. All the transition state calculations were performed using the DL-FIND program $^{37}$ included in the ChemShell package. ${ }^{38}$

\section{Results and discussion}

The characteristic structures of $\mathrm{NH}_{2} \mathrm{OH}$, identified on the $\mathrm{S}_{0}$ and $S_{1}$ potential energy curves, are labeled with a three-character code as $\mathbf{G k}-[\mathbf{1}], \mathbf{E k}-[\mathbf{1}]^{\neq}$, or $\left.\mathbf{E k - [ 1}\right]^{*}$, where $\mathbf{G}$ indicates a structure in the $\mathrm{S}_{0}$ state, $\mathbf{E}$ indicates one in the $\mathrm{S}_{1}$ state, and $\mathbf{k}$ indicates dissociation channels (1)-(7). Different $\mathrm{NH}_{2} \mathrm{OH}$ structures in the same dissociation channel are labeled [1], [2], etc. The * ${ }^{*}$, and $\neq$ symbols denote vertically excited structures, those at the intersection of the $S_{0}$ and $S_{1}$ potential energy curves, and transition structures, respectively. For instance, structures G1-[1]* and E1-[1 $]^{*}$ are identical structures $(\mathbf{l}=\mathbf{1})$ computed in the $\mathrm{S}_{0}$ (G) and $\mathrm{S}_{1}(\mathbf{E})$ states, respectively, involved in channel (1) $\mathrm{O}-\mathrm{H}$ dissociation $(\mathbf{k}=\mathbf{1})$. Instead, E2-[2]* and $\mathbf{E 2}-[4]^{\S}$ are different structures $(\mathbf{l}=\mathbf{2}$ and $\mathbf{4})$ on the $\mathrm{S}_{1}$ potential energy curve of $\mathrm{N}-\mathrm{O}$ dissociation $(\mathbf{k}=2)$; they are a vertically excited structure $\left({ }^{*}\right)$ and a structure at the $\mathrm{S}_{0}-\mathrm{S}_{1}$ state intersection (§), respectively.

The equilibrium structures of $\mathrm{NH}_{2} \mathrm{OH}$ in the electronic ground $\left(\mathrm{S}_{0}\right)$ and lowest singlet-excited $\left(\mathrm{S}_{1}\right)$ states, obtained from
CASPT2 $(10,9)$ geometry optimizations, are shown in Fig. 2 . The relax-scan potential energy curves and proposed mechanisms for the direct covalent bond dissociations are shown in Fig. 3 and 4 , respectively. The relax-scan potential energy curves and proposed mechanisms for the unimolecular-isomerization dissociations are illustrated in Fig. 5 and 6, respectively. The calculated CI coefficients are reported in Tables 1 and S1-S7 of the ESI. $\dagger$ Note that $\Psi_{0}$ and $\mathrm{C}_{0}$ indicate the electronic ground state, $\Psi_{\mathrm{a}}^{\mathrm{r}}$ and $\mathrm{C}_{\mathrm{a}}^{\mathrm{r}}$ indicate the a $\rightarrow \mathrm{r}$ singly excited state (S-type), and $\Psi_{\mathrm{a}, \mathrm{b}}^{\mathrm{r}, \mathrm{s}}$ and $\mathrm{C}_{\mathrm{a}, \mathrm{b}}^{\mathrm{r}, \mathrm{s}}$ indicate the a $\rightarrow \mathrm{r}$ and $\mathrm{b} \rightarrow \mathrm{s}$ doubly excited state (D-type). Indices $\mathrm{a} / \mathrm{r}$ and $\mathrm{b} / \mathrm{s}$ correspond to occupied and virtual (or unoccupied) spin orbitals, respectively; the presence or absence of a bar denotes beta ( $\beta)$ or alpha $(\alpha)$ spin orbitals, respectively. The classical and quantum rate constants and relative Gibbs free energies of the elementary reactions are reported in Tables S8-S11. $\dagger$ The vertical excitation energies and corresponding oscillator strengths of characteristic structures are included in Table S12.†

\section{Equilibrium structures}

Five equilibrium structures were obtained from the CASPT2 $(10,9)$ geometry optimizations in the $S_{0}$ and $S_{1}$ states (Fig. 2). Structure G1-[1] has $C_{\mathrm{S}}$ symmetry with $R_{\mathrm{N}-\mathrm{O}}=1.47 \AA$, $R_{\mathrm{O}-\mathrm{H}}=0.97 \AA, R_{\mathrm{N}-\mathrm{H}}=1.03 \AA, \angle \mathrm{HNH}=104.6^{\circ}, \angle \mathrm{HNO}=$ $102.4^{\circ}$, and $\angle \mathrm{NOH}=101.4^{\circ}$. These values are in excellent agreement with those obtained from previous ab initio calculations $\mathrm{s}^{39}$ and microwave spectra $\left(R_{\mathrm{N}-\mathrm{O}}=1.45 \AA, R_{\mathrm{O}-\mathrm{H}}=0.96 \AA\right.$,

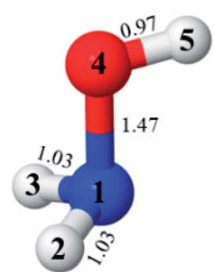

G1-[1]

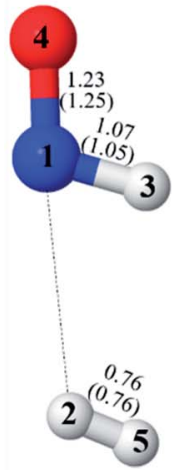

G6-[3]

(E6-[3])

$$
\begin{aligned}
& \mathrm{E}^{\mathrm{Ex}}=6.38 \mathrm{eV} \\
& (194 \mathrm{~nm}) \\
& \angle \mathrm{H}(2) \mathrm{NH}(3)=104.6^{\circ} \\
& \angle \mathrm{HNO}=102.4^{\circ} \\
& \angle \mathrm{NOH}(5)=101.4^{\circ}
\end{aligned}
$$

$\mathrm{E}^{\mathrm{Ex}}=1.59 \mathrm{eV}$ $(780 \mathrm{~nm})$ $\angle \mathrm{HNO}=107.9^{\circ}\left(115.1^{\circ}\right)$

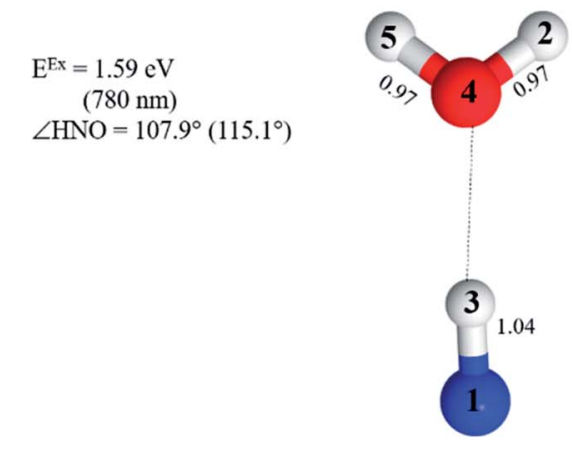

G7-[3]

(E7-[3])
$\mathrm{E}^{\mathrm{Ex}}=3.02 \mathrm{eV}$

$(411 \mathrm{~nm})$

$\angle \mathrm{H}(2) \mathrm{NH}(3)=\left(133.2^{\circ}\right)$

$\angle \mathrm{H}(2) \mathrm{NO}=\left(113.4^{\circ}\right)$

$\angle \mathrm{NOH}(5)=\left(103.4^{\circ}\right)$

E1-[1]

$\mathrm{E}^{\mathrm{Ex}}=0.00 \mathrm{eV}$

$\angle \mathrm{H}(3) \mathrm{OH}(5)=102.9^{\circ}$

$\angle \mathrm{NH}(2) \mathrm{O}=177.9^{\circ}$

$\angle \mathrm{H}(5) \mathrm{OH}(2)=120.2^{\circ}$

$\angle \mathrm{H}(3) \mathrm{OH}(2)=119.2^{\circ}$

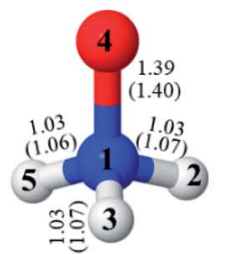

$\mathrm{E}^{\mathrm{Ex}}=4.13 \mathrm{eV}$ $(300 \mathrm{~nm})$ $\angle \mathrm{HNH}=107.0^{\circ}\left(109.3^{\circ}\right)^{a}$ $\angle \mathrm{HNO}=111.8^{\circ}\left(108.1^{\circ}\right)^{\mathrm{a}}$

Fig. 2 Equilibrium structures of $\mathrm{NH}_{2} \mathrm{OH}$ in the electronic ground $\left(\mathrm{S}_{0}\right)$ and lowest singlet-excited $\left(\mathrm{S}_{1}\right)$ states obtained from $\mathrm{CASPT2}(10,9)$ geometry optimizations. Distances and angles are in $\AA$ and degree, respectively. (...) are the values obtained in the $\mathrm{S}_{1}$ state. The three-character codes are explained in the text. $E^{\mathrm{Ex}}=\mathrm{S}_{0} \rightarrow \mathrm{S}_{1}$ vertical excitation energy. ${ }^{c} \mathrm{O}-\mathrm{H}$ distance constrained in the geometry optimization. 
a)
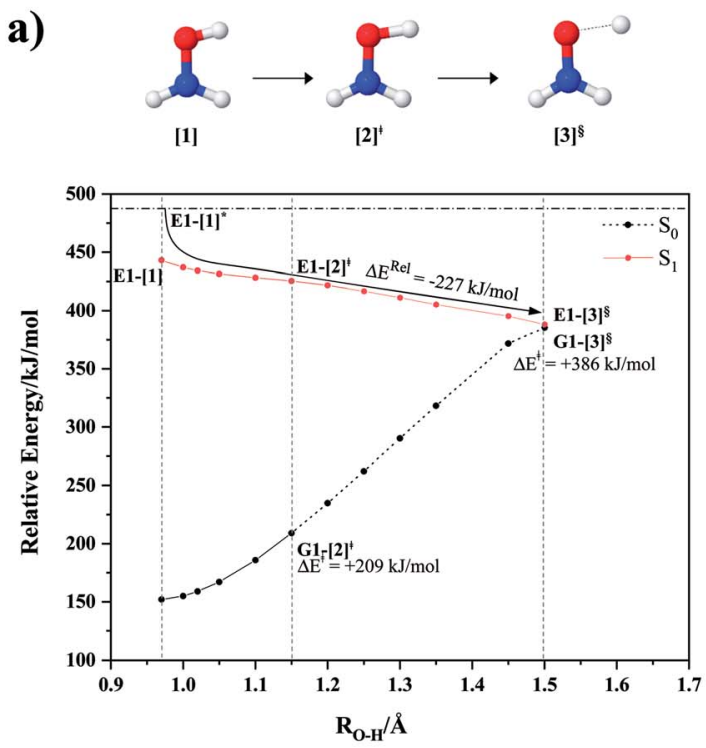

c)

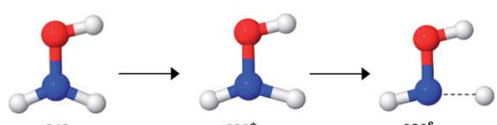

[1]

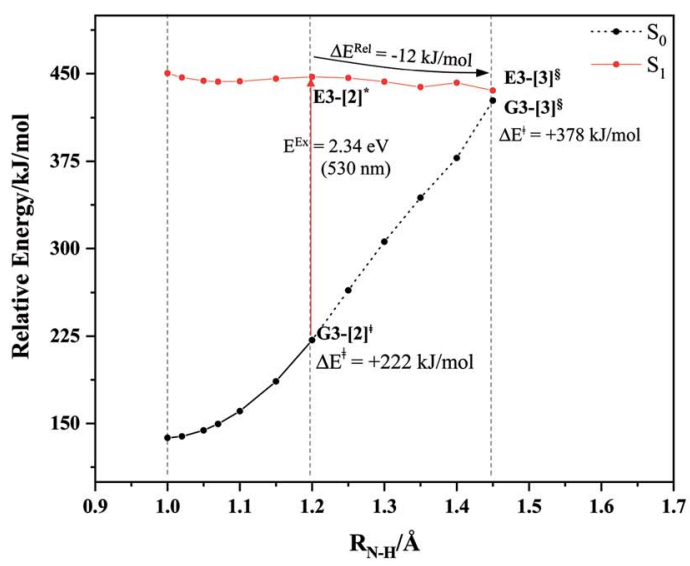

b)
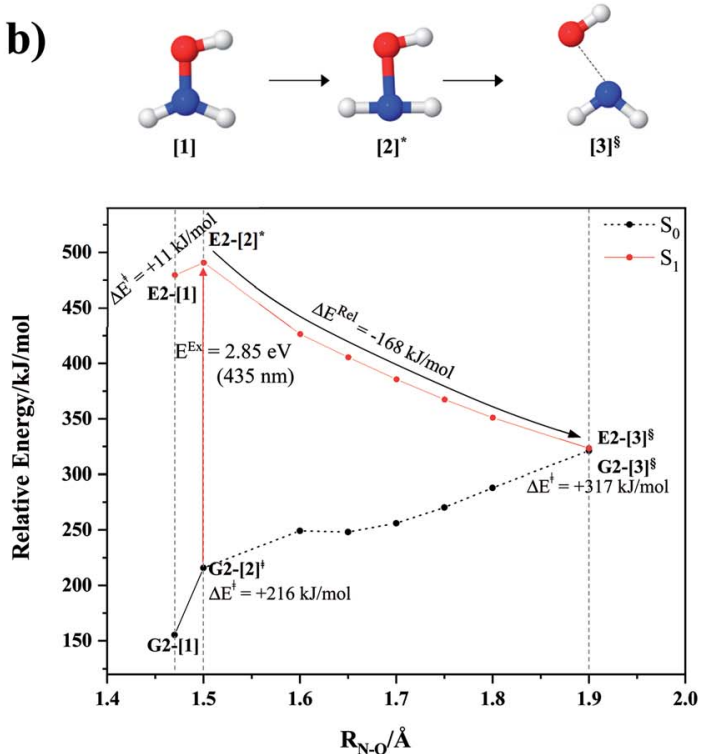

d)

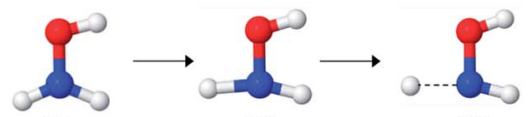

[2]

$[3]^{\S}$

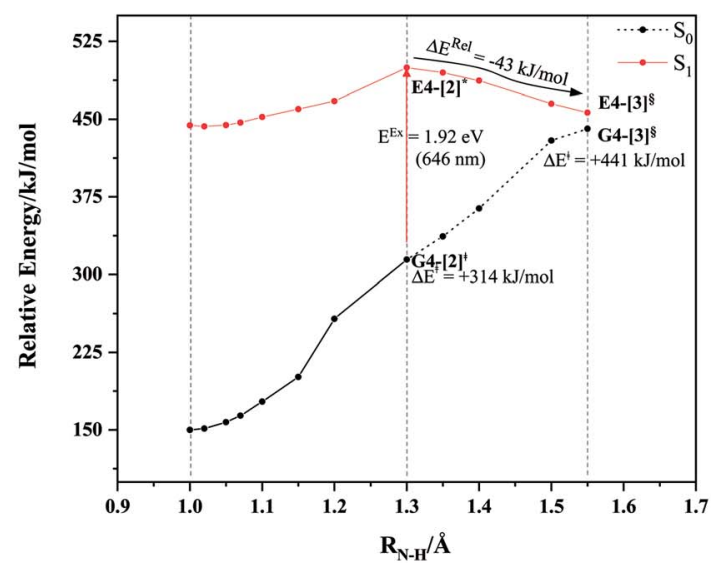

Fig. 3 The $\mathrm{S}_{1}$ relax-scan potential energy curves for the direct covalent bond dissociations in $\mathrm{NH}_{2} \mathrm{OH}$ obtained from CASPT2(10,9) calculations. The energies on the $S_{0}$ potential energy curves were calculated at the same geometries. The three-character codes are explained in the text. $\neq=$ transition structure; $\S=$ structure at the intersection of the $S_{0}$ and $S_{1}$ potential energy curves; $\Delta E^{\text {Rel }}=$ relative energy with respect to the vertically excited precursor in the $\mathrm{S}_{1}$ state; $\Delta E^{\neq}=$energy barrier with respect to structure G1-[1]; $\mathrm{S}_{0}$ and $\mathrm{S}_{1}=$ relative energies with respect to the total energy of structure G1-[1], obtained from CASPT2 $(10,9)$ calculations in the $\mathrm{S}_{0}$ and $\mathrm{S}_{1}$ states, respectively. $(a-d) \mathrm{O}-\mathrm{H}, \mathrm{N}-\mathrm{O}, \mathrm{N}-\mathrm{H}^{\text {cis }}$ and $\mathrm{N}-\mathrm{H}^{\text {trans }}$ dissociations, channels (1)-(4), respectively.

$R_{\mathrm{N}-\mathrm{H}}=1.02 \AA, \angle \mathrm{HNH}=107.1^{\circ}, \angle \mathrm{HNO}=103.2^{\circ}$, and $\angle \mathrm{NOH}=$ $\left.101.4^{\circ}\right) .^{40}$ For structure G1-[1], the CASPT2 $(10,9)$ method yields an $\mathrm{S}_{0} \rightarrow \mathrm{S}_{1}$ vertical excitation energy $\left(E^{\mathrm{Ex}}\right)$ of $6.38 \mathrm{eV}(194 \mathrm{~nm})$ with the highest oscillator strength compared with other characteristic structures (Table S12 $\dagger$ ). These results are in excellent agreement with the photodissociation of $\mathrm{NH}_{2} \mathrm{OH}$ caused by UV absorption at $193 \mathrm{~nm}(6.42 \mathrm{eV}) .^{5}$

Although $\mathrm{NH}_{2} \mathrm{OH}$ is not stable in the $\mathrm{S}_{1}$ state and preferentially dissociates into $\mathrm{NH}_{2} \mathrm{O}$ and $\mathrm{H}$, the CASPT2 $(10,9)$ geometry was optimized in this state, constraining the $\mathrm{O}-\mathrm{H}$ distance to its ground state equilibrium value $(0.97 \AA)$, because the corresponding structural and energetic data can be used to understand the photodissociation mechanisms. Although the $\mathrm{N}-\mathrm{H}$ and $\mathrm{N}-\mathrm{O}$ distances do not change substantially, the threedimensional (3-D) $S_{0}$ structure G1-[1] is transformed into the planar (2-D) structure E1-[1] of Fig. 2, with a considerably lower vertical excitation energy $\left(E^{\mathrm{Ex}}\right)$ of $3.02 \mathrm{eV}(411 \mathrm{~nm})$. The change of the $\mathrm{NH}_{2} \mathrm{OH}$ equilibrium structure upon $\mathrm{S}_{0} \rightarrow \mathrm{S}_{1}$ excitation (3$\mathrm{D} \rightarrow 2$-D) makes it unreasonable to use the freeze-scan method in the construction of the potential energy curves in the excited states.

The CI coefficients of Table 1 evidence that, for structure G1$[1]$, the electronic ground state, $\Psi_{0}$, dominates $\left(\mathrm{C}_{0}=0.9727\right)$, with a small contribution from the doubly excited $\Psi_{\overline{8}, 8}^{\overline{11}, 11}$ state 


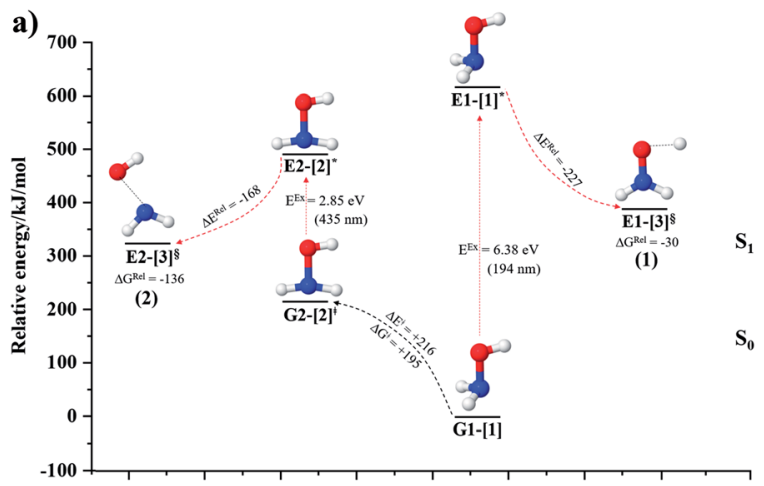

b)

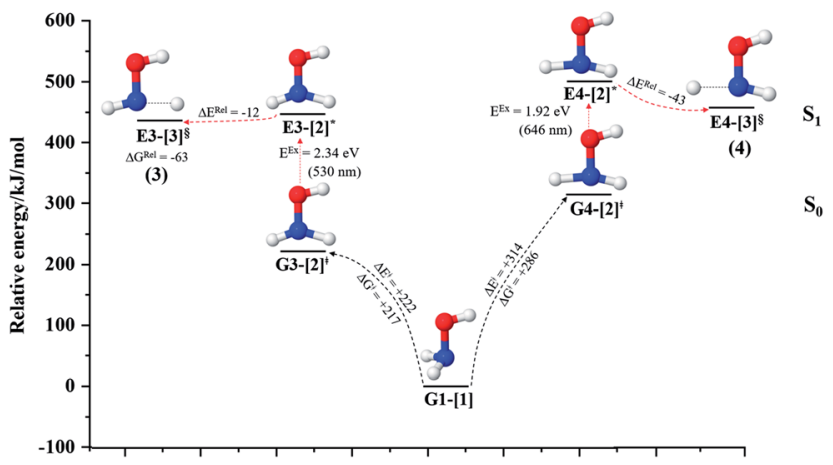

Fig. 4 Mechanisms for the direct covalent bond dissociations in $\mathrm{NH}_{2} \mathrm{OH}$ obtained from the analysis of the $S_{0}$ and $S_{1}$ potential energy curves and transition state theories (TST). $\neq=$ transition structure; $\S=$ structure at the intersection of the $S_{0}$ and $S_{1}$ potential energy curves; $\Delta E^{\neq}=$energy barrier with respect to structure G1-[1]; $\Delta G^{\neq}=$relative Gibbs free energy barrier with respect to structure G1-[1] at $1200 \mathrm{~K}$; $\Delta G^{\mathrm{Rel}}=$ relative Gibbs free energy with respect to the precursor at $1200 \mathrm{~K} ; E^{\mathrm{Ex}}=$ vertical excitation energy; (...) = dissociation channel. (a) Channels (1)-(2). (b) Channel (3)-(4).

$\left(C_{\overline{8}, 8}^{\overline{11}, 11}=0.1174\right)$. For comparison, the same structure in the $S_{1}$ state is characterized by a singly excited $\Psi_{\overline{9}}^{\overline{10}}$ state $\left(\mathrm{C}_{\overline{9}}^{\overline{10}}=0.9658\right)$ with a small contribution from the excitation of two electrons of the HOMO-1 orbital $\left(n_{\text {orb }}=8\right)$, $\Psi_{\overline{9}, 8, \overline{8}}^{\overline{10}, 11, \overline{11}}\left(\mathrm{C}_{\overline{9}, 8, \overline{8}}^{\overline{10}, 11, \overline{11}}=0.1207\right)$. The interference of the primary electronic states with higher electronic excited states confirms the importance of describing the multiconfigurational character of $\mathrm{NH}_{2} \mathrm{OH}$. For structure G1-[1], this interference is approximately $12 \%$ in both the $S_{0}$ and $S_{1}$ states.

CASPT2 $(10,9)$ geometry optimizations reveal that $\mathrm{NH}_{3} \mathrm{O}$ with $C_{3 \mathrm{v}}$ symmetry is stable in both the $\mathrm{S}_{0}$ and $\mathrm{S}_{1}$ states. The $\mathrm{S}_{0}$ state of structure G5-[3], shown in Fig. 2 , has $R_{\mathrm{N}-\mathrm{O}}=1.39 \AA, R_{\mathrm{N}-\mathrm{H}}=$ $1.03 \AA, \angle \mathrm{HNH}=107.0^{\circ}$, and $\angle \mathrm{HNO}=111.8^{\circ}$, in excellent agreement with mass spectroscopic experiments and G2-like $a b$ initio calculations $\left(R_{\mathrm{N}-\mathrm{O}}=1.35 \AA, R_{\mathrm{N}-\mathrm{H}}=1.03 \AA\right.$, and $\angle \mathrm{HNO}=$ $\left.113.7^{\circ}\right) .{ }^{12}$ For structure G5-[3], the CASPT2 $(10,9)$ method yields a vertical excitation energy $\left(E^{\mathrm{Ex}}\right)$ of $4.13 \mathrm{eV}(300 \mathrm{~nm})$. The $\mathrm{S}_{0} \rightarrow$ $\mathrm{S}_{1}$ excitation leads to structure E5-[3], with small changes in the covalent bond distances and angles: $R_{\mathrm{N}-\mathrm{O}}=1.40 \AA, R_{\mathrm{N}-\mathrm{H}}=1.07$ $\AA, \angle \mathrm{HNH}=109.3^{\circ}$, and $\angle \mathrm{HNO}=108.1^{\circ}$. Analysis of the CI coefficients listed in Table 1 shows an electronic state interference similar to the case of G1-[1]: structure G5-[3] is characterized by $\Psi_{0}\left(\mathrm{C}_{0}=0.9729\right)$, with a small contribution from the doubly excited $\Psi_{\overline{8}, 8}^{\overline{11}, 11}$ state $\left(\mathrm{C}_{\overline{8}, 8}^{\overline{11}, 11}=0.0973\right)$, whereas, in the $\mathrm{S}_{1}$ state, $\Psi_{\overline{9}}^{\overline{10}}\left(\mathrm{C}_{\overline{9}}^{\overline{10}}\right)^{8,8}=0.9728$ dominates, with a small contribution from $\Psi_{\overline{9}, 8, \overline{8}}^{\overline{10}, 11, \overline{11}}\left(\mathrm{C}_{\overline{9}, 8, \overline{10}}^{\overline{10}, 11, \overline{11}}=0.1119\right)$.

The CASPT2(10,9)-optimized structures of the $\mathrm{HNO}-\mathrm{H}_{2}$ complex are nearly identical in the $\mathrm{S}_{0}$ and $\mathrm{S}_{1}$ states, as evidenced by structures G6-[3] and E6-[3] of Fig. 2: in the $\mathrm{S}_{0}$ state, $R_{\mathrm{N}-\mathrm{O}}=$ $1.23 \AA, R_{\mathrm{N}-\mathrm{H}}=1.07 \AA$, and $\angle \mathrm{HNO}=107.9^{\circ}$, with a vertical excitation energy ( $\left.E^{\mathrm{Ex}}\right)$ of $1.59 \mathrm{eV}(780 \mathrm{~nm})$; in the $\mathrm{S}_{1}$ state, $R_{\mathrm{N}-\mathrm{O}}$ $=1.25 \AA, R_{\mathrm{N}-\mathrm{H}}=1.05 \AA$, and $\angle \mathrm{HNO}=115.1^{\circ}$. The equilibrium geometries and $E^{\mathrm{Ex}}$ are compatible with the results obtained from absorption in the 650-770 nm range $\left(R_{\mathrm{N}-\mathrm{O}}=1.21 \AA, R_{\mathrm{N}-\mathrm{H}}\right.$ $=1.06 \AA, \angle \mathrm{HNO}=109^{\circ}$, and $\left.E^{\mathrm{Ex}}=1.91-1.61 \mathrm{eV}\right) .{ }^{18}$ The CI coefficients listed in Table 1 reveal that, in the $S_{0}$ state, the electronic ground state $\Psi_{0}\left(\mathrm{C}_{0}=0.9493\right)$ dominates with $\sim 21 \%$ contributions from the closed-shell excited $\Psi_{\overline{8}, 8}^{\overline{10}, 10}$ state $\left(\mathrm{C}_{\overline{8}, 8}^{\overline{10}, 10}=0.1960\right)$. In the $\mathrm{S}_{1}$ state, the same structure is represented by $\Psi_{\overline{9}}^{\overline{10}}\left(\mathrm{C}_{\overline{9}}^{\overline{10}}=0.9557\right)$, with a small contribution from $\Psi_{9, \overline{8}}^{10, \overline{10}}\left(\mathrm{C}_{9, \overline{8}}^{10, \overline{10}}=0.0772\right)$. In this case, the patterns of the CI coefficients differ from those of the previously discussed structures: the primary electronic states interfere with excitations of two electrons from the lone-pair orbital of the $\mathrm{O}$ atom $\left(n_{\text {orb }}=8\right)$ to a dissociated-valence orbital $\left(n_{\text {orb }}=11\right)$.

Excellent agreement with previous theoretical and experimental data is also found for the $\mathrm{NH}-\mathrm{H}_{2} \mathrm{O}$ complex. In this case, the equilibrium geometries obtained from CASPT2 $(10,9)$ optimization in the $S_{0}$ and $S_{1}$ states are identical, as shown for structure G7-[3] in Fig. 2, with $R_{\mathrm{N}-\mathrm{H}}=1.04 \AA, R_{\mathrm{O}-\mathrm{H}}=0.97 \AA$, $\angle \mathrm{HOH}=102.9^{\circ}$, and $E^{\mathrm{Ex}}=0 \mathrm{eV}$. The patterns of the CI coefficients of structure G7-[3] are the same as those of structures G1-[1], E1-[1], and G5-[3].

Collectively, the structural results, the energetic ones, and the electronic states discussed above confirm the accuracy of the CASPT2 $(10,9) /$ aug-cc-pVDZ framework and its applicability to study the photodissociation of $\mathrm{NH}_{2} \mathrm{OH}$ in the $\mathrm{S}_{0}$ and $\mathrm{S}_{1}$ states.

\section{O-H dissociation}

The $\mathrm{O}-\mathrm{H}$ dissociation in the $\mathrm{S}_{1}$ state is represented by a purely repulsive potential energy curve, as shown in Fig. 3a. Assuming that $\mathrm{NH}_{2} \mathrm{OH}$ completely dissociates into $\mathrm{NH}_{2} \mathrm{O}$ and $\mathrm{H}$ in their electronic ground states at the intersection of the $\mathrm{S}_{0}$ and $\mathrm{S}_{1}$ states (structure $\mathbf{E 1}-[3]^{\S}$, with $E^{\mathrm{Ex}} \approx 0 \mathrm{eV}$ ), the potential energy for the O-H dissociation relative to the vertically excited structure E1-[1]* is $\Delta E^{\mathrm{Rel}}=-227 \mathrm{~kJ} \mathrm{~mol}^{-1}$. Instead, in the $\mathrm{S}_{0}$ state, the energy barrier $\left(\Delta E^{\neq}\right)$with respect to the ground-state equilibrium structure G1-[1] is $386 \mathrm{~kJ} \mathrm{~mol}^{-1}$. The rate constants and relative Gibbs free energies of Tables $\mathrm{S} 8$ and $\mathrm{S} 9 \dagger$ confirm that $\mathrm{NH}_{2} \mathrm{OH}$ becomes a photoacid through $\mathrm{S}_{0} \rightarrow \mathrm{S}_{1}$ vertical excitation at $194 \mathrm{~nm}(6.38$ $\mathrm{eV}$ ), and that the nonradiative relaxation of excited $\mathrm{NH}_{2} \mathrm{OH}$ into ground-state $\mathrm{NH}_{2} \mathrm{O}$ and $\mathrm{H}$ is thermodynamically favorable: for instance, at $1200 \mathrm{~K}, \Delta G^{\mathrm{Rel}}=-30 \mathrm{~kJ} \mathrm{~mol}^{-1}$. Oppositely, the thermal dissociation of the $\mathrm{O}-\mathrm{H}$ bond in the $\mathrm{S}_{0}$ state is thermodynamically and kinetically unfavorable: e.g., at $1200 \mathrm{~K}, \Delta G^{\neq}=$ $437 \mathrm{~kJ} \mathrm{~mol}^{-1}$ and $k^{\mathrm{Q}-\mathrm{vib}}=2.46 \times 10^{-6} \mathrm{~s}^{-1}$.

Examination of the $S_{0}$ and $S_{1}$ potential energy curves reveals inflection points at $\mathrm{O}-\mathrm{H}$ distance $R_{\mathrm{O}-\mathrm{H}}=1.15 \AA$. Analysis of the 
a)
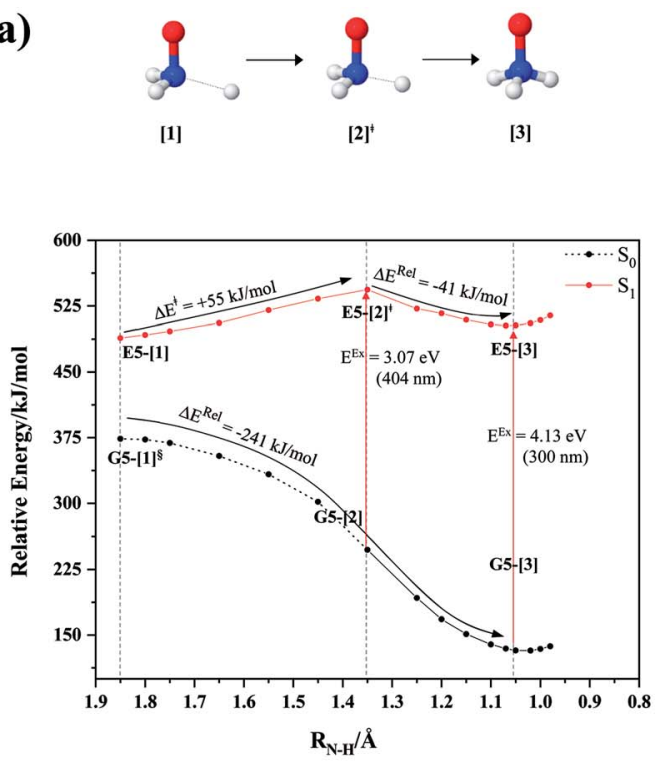

b)
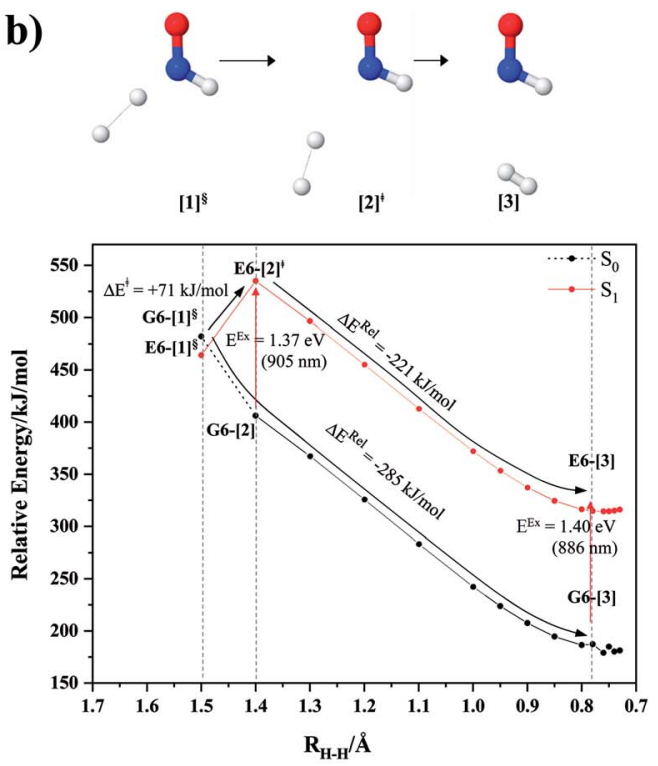

c)
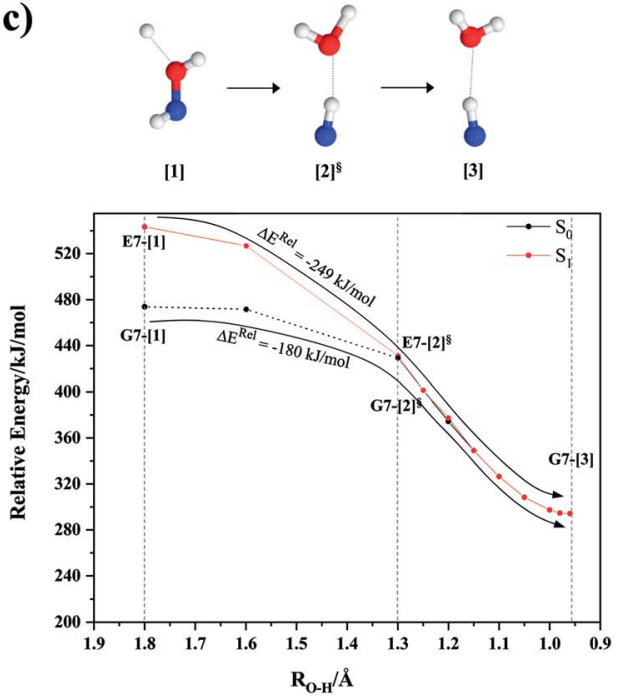

Fig. 5 The $\mathrm{S}_{1}$ relax-scan potential energy curves for the unimolecular-isomerization dissociations in $\mathrm{NH}_{2} \mathrm{OH}$ obtained from $\mathrm{CASPT} 2(10,9)$ calculations. The energies on the $S_{0}$ potential energy curves were calculated at the same geometries. The three-character codes are explained in the text. $\neq=$ transition structure; $\S=$ structure at the intersection of the $S_{0}$ and $S_{1}$ potential energy curves; $\Delta E^{\text {Rel }}=$ relative energy with respect to precursor or transition structure; $\Delta E^{\neq}=$energy barrier with respect to precursor; $\mathrm{S}_{0}$ and $\mathrm{S}_{1}=$ relative energies with respect to the total energy of structure G1-[1], obtained from CASPT2 $(10,9)$ calculations in the $S_{0}$ and $S_{1}$ states, respectively. (a-c) Unimolecular-isomerization dissociations in channels (5)-(7), respectively.

CI coefficients of the characteristic structures (Table S1 $\dagger$ ) shows that, in the $\mathrm{S}_{0}$ state, the planar structure with $R_{\mathrm{O}-\mathrm{H}}=0.97 \AA$ is dominated by the electronic ground state $\Psi_{0}\left(\mathrm{C}_{0}=0.9789\right)$, whereas the singly excited $\Psi_{\overline{9}}^{\overline{10}}$ state $\left(\mathrm{C}_{\overline{9}}^{\overline{10}}=0.9715\right)$ dominates the $\mathrm{S}_{1}$ state. As the $\mathrm{O}-\mathrm{H}$ distance increases to $R_{\mathrm{O}-\mathrm{H}}=1.15 \AA$, the electronic states associated with excitations of an electron of the $\mathrm{O}$ lone-pair orbital $\left(n_{\text {orb }}=8\right), \quad \Psi_{\overline{8}}^{\overline{10}}\left(\mathrm{C}_{\overline{8}}^{\overline{10}}=0.0649\right)$ and $\Psi_{9, \overline{8}}^{10, \overline{10}}\left(\mathrm{C}_{9, \overline{8}}^{10, \overline{10}}=0.0844\right)$, appear in the $\mathrm{S}_{0}$ and $\mathrm{S}_{1}$ states, respectively, having their maximum contribution at the intersection of the $\mathrm{S}_{0}$ and $\mathrm{S}_{1}$ states, $\mathrm{C}_{\overline{8}}^{\overline{10}}=0.2293$ and $\mathrm{C}_{9, \overline{8}}^{10, \overline{10}}=0.2441$. Therefore, structure E1-[2] $]^{\neq}$can be considered as a transition structure and $R_{\mathrm{O}-\mathrm{H}}=1.15 \AA$ as the threshold $\mathrm{O}-\mathrm{H}$ distance for Rydberg orbital evolution, ${ }^{7}$ beyond which $\mathrm{O}-\mathrm{H}$ in $\mathrm{NH}_{2} \mathrm{OH}$ dissociates. In this case, the Rydberg orbital $\left(n_{\text {orb }}=10\right)$ is the natural orbital related to the dissociated $\mathrm{H}$ atom. The Gibbs free energy barrier for the Rydberg orbital evolution in the $\mathrm{S}_{0}$ state at $1200 \mathrm{~K}$ is $\Delta G^{\neq}=210 \mathrm{~kJ} \mathrm{~mol}^{-1}$, with $k^{\mathrm{Q}-\text { vib }}=1.82 \times 10^{4} \mathrm{~s}^{-1}$ (Table S8†).

It is noteworthy that the conversion of the transition structure into the dissociated products is characterized by significant contributions from excitations of an electron in the lone-pair orbital of the $\mathrm{O}$ atom $\left(n_{\text {orb }}=8\right)$ to the Rydberg orbital $\left(n_{\text {orb }}=\right.$ 10). For example, in the $S_{1}$ state, though the contribution of primary electronic state $\Psi_{\overline{9}}^{\overline{10}}$ gradually decreases from $\mathrm{C}_{\overline{9}}^{\overline{10}}=0.9715$ to 0.9659 and 0.9463 for structures E1-[1], E1$[2]^{\neq}$, and $\mathbf{E} 1-[3]^{\S}$, respectively, the contribution of the next 
a)
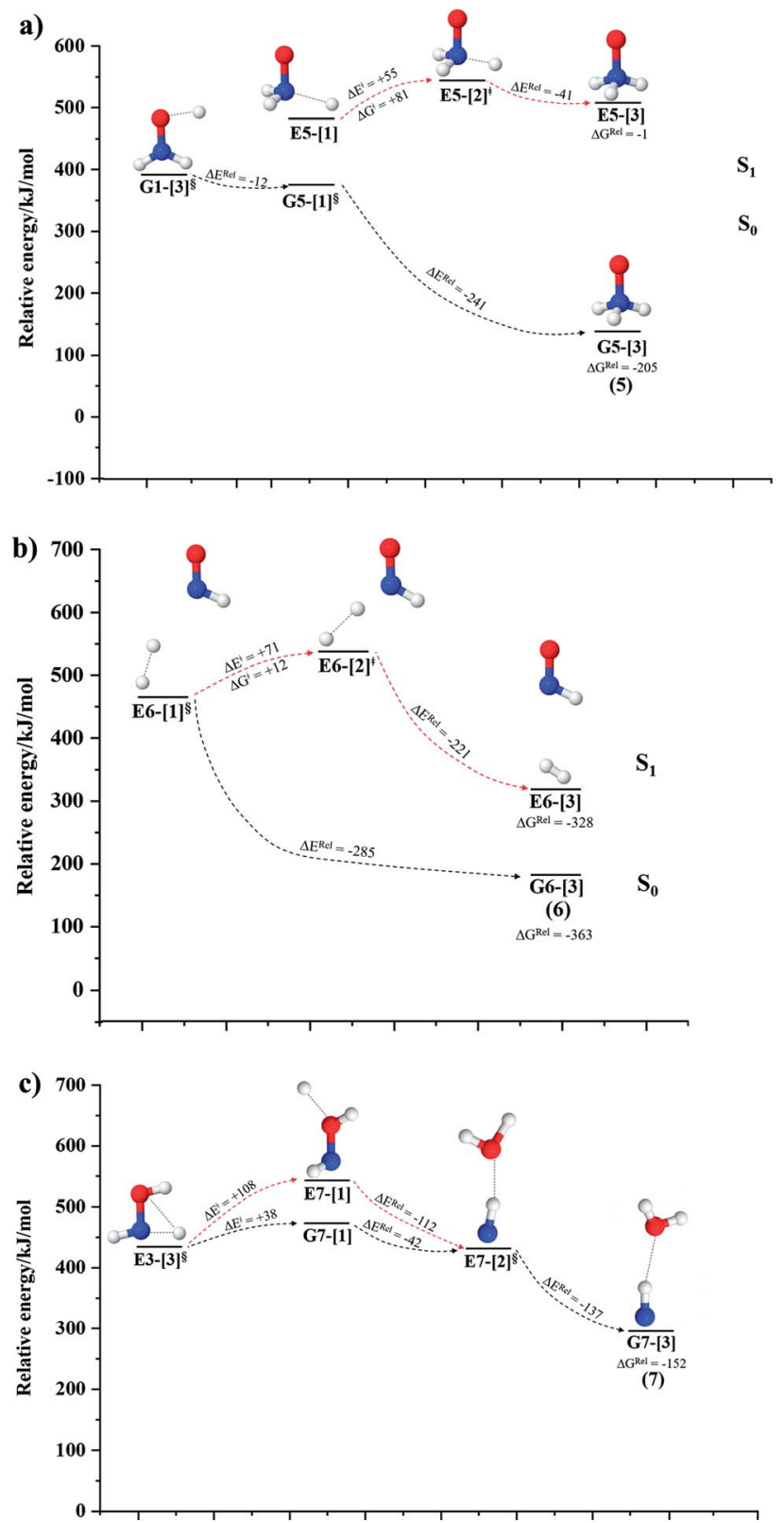

Fig. 6 Mechanisms for the unimolecular-isomerization dissociations in $\mathrm{NH}_{2} \mathrm{OH}$ obtained from the analysis of the $\mathrm{S}_{0}$ and $\mathrm{S}_{1}$ potential energy curves and transition state theories (TST). $\neq=$ transition structure; $\S=$ structure at the intersection of the $S_{0}$ and $S_{1}$ potential energy curves: $\Delta E^{\neq}=$energy barrier with respect to precursor; $\Delta G^{\neq}=$relative Gibbs free energy barrier with respect to precursor at $1200 \mathrm{~K} ; \Delta G^{\text {Rel }}=$ relative Gibbs free energy with respect to the precursor at $1200 \mathrm{~K} ;(\ldots)=$ dissociation channel. (a-c) Channels (5)-(7), respectively.

excited state, $\Psi_{9, \overline{8}}^{10, \overline{10}}$, increases significantly from $\mathrm{C}_{9, \overline{8}}^{10, \overline{10}}=0.0844$ to 0.2441 (nearly $300 \%$ ) for transition structure E1- $[2]^{\neq}$and product E1-[3] $]^{\S}$. These values will be used as guidelines to discuss direct covalent bond dissociation and isomerization-dissociation.

\section{N-O dissociation}

Fig. $3 \mathrm{~b}$ shows the $\mathrm{S}_{1}$ potential energy curve obtained from the CASPT2 $(10,9)$ calculations. A maximum is seen at $R_{\mathrm{N}-\mathrm{O}}=1.50 \AA$
Table 1 Equilibrium structures of $\mathrm{NH}_{2} \mathrm{OH}$ and leading $\mathrm{Cl}$ coefficients obtained from the CASPT2 $(10,9)$ method in the $\mathrm{S}_{0}$ and $\mathrm{S}_{1}$ states. $\Psi_{0}=$ electronic ground state; $\Psi_{\mathrm{a}}^{\mathrm{r}}=\mathrm{a} \rightarrow \mathrm{r}$ singly excited state (S-type); $\Psi_{\mathrm{a}, \mathrm{b}}^{\mathrm{r}, \mathrm{s}}=\mathrm{a} \rightarrow \mathrm{r}$ and $\mathrm{b} \rightarrow \mathrm{s}$ doubly excited state (D-type); the indices $\mathrm{a}$ and $b$, and $r$ and $s$ label occupied and virtual or unoccupied spin orbitals, respectively; a bar or lack of a bar is to denote beta $(\beta)$ and alpha $(\alpha)$ spin orbitals, respectively

\begin{tabular}{|c|c|c|c|c|}
\hline \multirow[b]{2}{*}{ Structures } & \multicolumn{2}{|l|}{$\mathrm{S}_{0}$} & \multicolumn{2}{|l|}{$\mathrm{S}_{1}$} \\
\hline & Conf. & CI coeff. & Conf. & CI coeff. \\
\hline \multirow[t]{2}{*}{ G1-[1] } & $\Psi_{0}$ & 0.9727 & $\Psi_{\overline{9}}^{\overline{10}}$ & 0.9658 \\
\hline & $\Psi_{\overline{8}, 8}^{\overline{11}, 11}$ & 0.1174 & $\Psi_{\overline{9}, 8, \overline{8}}^{\overline{10}, 11, \overline{11}}$ & 0.1207 \\
\hline
\end{tabular}

E1-[1]
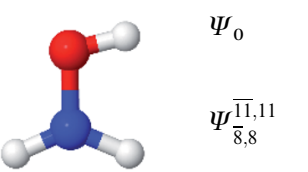

0.9789

0.0764

$\Psi_{\overline{9}}^{\overline{10}}$

0.9715

0.0694

G6-[3]

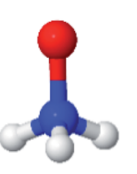

$\Psi_{0}$

$\Psi_{\overline{8}, 8}^{\overline{11}, 11}$

0.097

0.9729

$\Psi_{\overline{9}}^{\overline{10}}$

$\Psi_{\overline{9}, 8, \overline{8}}^{\overline{10}, 11, \overline{11}}$

0.0694

G6-[3]

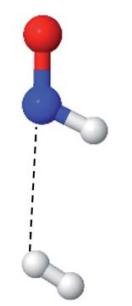

$\Psi_{0}$

$\Psi_{\overline{8}, 8}^{\overline{10}, 10}$

0.9493

$\Psi_{\overline{9}}^{\overline{10}}$

$\Psi_{\overline{9}, 8, \overline{8}}^{\overline{10}, 11, \overline{11}}$

0.1119

$\Psi \frac{\overline{10}}{\overline{8}}$

0.196

$\Psi_{9, \overline{8}}^{10, \overline{10}}$

0.0772

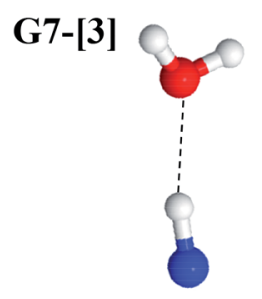

0.6956

0.0510
$\Psi_{\overline{9}}^{\overline{10}}$

$\Psi_{\overline{9}, 8, \overline{8}}^{\overline{10}, 11, \overline{11}}$
0.9790

0.0718<smiles>[AsH3]</smiles>

(structure E2-[2]*) with $\Delta E^{*}=11$ and $\Delta E^{\mathrm{Rel}}=-168 \mathrm{~kJ} \mathrm{~mol}^{-1}$ at the intersection of the $\mathrm{S}_{0}$ and $\mathrm{S}_{1}$ states, resulting in structure E2$[3]^{\S}$ and G2-[3] with $R_{\mathrm{N}-\mathrm{O}}=1.90 \AA$ A. However, the energy barrier for $\mathbf{G 2}-[3]^{\S}$ formation through $\mathrm{N}-\mathrm{O}$ dissociation in the $\mathrm{S}_{0}$ state is $\Delta E^{\neq}=317 \mathrm{~kJ} \mathrm{~mol}^{-1}$ (Fig. $3 \mathrm{~b}$ ). We recall that the $\mathrm{S}_{1}$ potential energy curve for $\mathrm{N}-\mathrm{O}$ dissociation was calculated by constraining the $\mathrm{O}-\mathrm{H}$ distance to $0.97 \AA$ because, in the absence of this constraint, the reaction preferentially proceeds towards $\mathrm{O}-\mathrm{H}$ dissociation. To confirm that structure E2-[2]* is the transition structure for $\mathrm{N}-\mathrm{O}$ dissociation in the $\mathrm{S}_{1}$ state, CASPT2 $(10,9)$ geometrical optimizations were performed with no geometrical 
constraints and starting from slightly shifted $R_{\mathrm{N}-\mathrm{O}}$ values of 1.45 and $1.55 \AA$. For $R_{\mathrm{N}-\mathrm{O}}=1.45 \AA$, the results show that structure E2$[2]^{*}$ relaxes to structure E1-[3] $]^{\S}$ (the $\mathrm{O}-\mathrm{H}$ dissociated structure). Instead, for $R_{\mathrm{N}-\mathrm{O}}=1.55 \AA, \mathrm{N}-\mathrm{O}$ dissociation occurs, yielding $\mathrm{NH}_{2}$ and $\mathrm{OH}$ (structure E2-[3] $]^{\S}$ ).

Overall, these results imply that $\mathrm{N}-\mathrm{O}$ dissociation cannot proceed directly through the $\mathrm{S}_{0} \rightarrow \mathrm{S}_{1}$ vertical excitation of structure G1-[1]. However, the $S_{0}$ and $S_{1}$ potential energy curves shown in Fig. 3b suggest an alternative pathway to avoid the $\mathrm{O}-\mathrm{H}$ dissociation shown in Fig. 4a. In fact, equilibrium structure G1-[1] in the $S_{0}$ state could be thermally excited and form a precursor in the $\mathrm{S}_{0}$ state, i.e., structure $\mathbf{G 2}-[2]^{\neq}$. This structure can be vertically excited to structure E2-[2]* with $E^{\mathrm{Ex}}=2.85 \mathrm{eV}$ (435 nm), nonradiatively relaxing along a purely repulsive potential energy curve into products $\mathrm{NH}_{2}$ and $\mathrm{OH}$ in their respective electronic ground states (structure E2-[3] $]^{\S}$ ) with $\Delta G^{\mathrm{Rel}}$ $=-136 \mathrm{~kJ} \mathrm{~mol}^{-1}$ (Table S9†). Because the $\mathrm{N}-\mathrm{O}$ dissociation of structure E2-[2]* is barrierless and spontaneous in the $S_{1}$ state, the thermal excitation is the process that determines the rate of generation of structure $\mathbf{G 2}-[2]^{\neq}$; at $1200 \mathrm{~K}, \Delta G^{\neq}=195 \mathrm{~kJ} \mathrm{~mol}^{-1}$ and $k^{\mathrm{Q} \text {-vib }}=7.75 \times 10^{4} \mathrm{~s}^{-1}$ (Table S8 $\dagger$ ). The photolytic mechanism of the $\mathrm{N}-\mathrm{O}$ bond at $435 \mathrm{~nm}$ is supported by the value of the threshold wavelength that generates $\mathrm{NH}_{2}$ and $\mathrm{OH}$ from the photoexcitation of $\mathrm{NH}_{2} \mathrm{OH}, \lambda_{\text {thres }}=463 \mathrm{~nm}(2.68 \mathrm{eV}) .^{7,41}$

The values of the CI coefficients listed in Table $\mathrm{S} 2 \uparrow$ for the $\mathrm{N}-\mathrm{O}$ dissociation show multiconfigurational trends along the potential energy curves, similar to the $\mathrm{O}-\mathrm{H}$ dissociation. For example, in the $S_{1}$ state, as the contribution of the primary electronic excited $\Psi_{\overline{9}}^{\overline{10}}$ state gradually changes from $\mathrm{C}_{9}^{\overline{10}}=0.9453$ to 0.9590 and 0.9312 for structures E2-[1], E2$[2]^{*}$, and $\mathbf{E} 2-[3]^{\S}$, respectively, the contributions arising from excitations of one or two electrons from the HOMO-1 (e.g., $\left.\Psi_{\overline{9}, 8 \overline{8}}^{\overline{10}, 11, \overline{11}}\right)$ significantly increase when transition structure E2-[2]* with $\mathrm{C}_{\overline{9}, 8, \overline{8}}^{\overline{10}, 1, \overline{11}}=0.1202$ is converted into structure $\mathbf{E} 2-[3]^{\S}$ (the $\mathrm{N}-\mathrm{O}$ dissociated structure) with $\mathrm{C}_{9, \overline{8}}^{10, \overline{10}}=0.2852$. The finding that structure E2-[2]* (with $R_{\mathrm{N}-\mathrm{O}}=1.50 \AA$ ) in the $\mathrm{S}_{1}$ state is represented by a slightly longer $\mathrm{N}-\mathrm{O}$ distance than the equilibrium value (because of Rydberg orbital evolution at $R_{\mathrm{N}-\mathrm{O}}$ slightly longer than $1.47 \AA$ ) is consistent with previous ab initio calculations using the CASSCF method, which suggested that the Rydberg-valence intersection is close to the $\mathrm{N}-\mathrm{O}$ equilibrium value. ${ }^{7}$

\section{N-H dissociation}

Two possible $\mathrm{N}-\mathrm{H}$ dissociation pathways have been considered: $\mathrm{N}-\mathrm{H}(2)$ and $\mathrm{N}-\mathrm{H}(3)$, hereafter referred to as $\mathrm{N}-\mathrm{H}^{\text {cis }}$ and $\mathrm{N}-\mathrm{H}^{\text {trans }}$ dissociations, respectively. Fig. $3 \mathrm{c}$ shows that for the $\mathrm{N}-\mathrm{H}^{\text {cis }}$ dissociation, the $S_{1}$ potential energy curve with constrained O-H distance $\left(R_{\mathrm{O}-\mathrm{H}(5)}=0.97 \AA\right)$ has a maximum at $R_{\mathrm{N}-\mathrm{H}(2)}=1.20$ $\AA$ (structure E3-[2]*) with $\Delta E^{\mathrm{Rel}}=-12 \mathrm{~kJ} \mathrm{~mol}^{-1}$ at the intersection of the $\mathrm{S}_{0}$ and $\mathrm{S}_{1}$ states, yielding structure E3-[3] $]^{\S}$ with $R_{\mathrm{N}-}$ $\mathrm{H}(2)=1.45 \AA$. In the $\mathrm{S}_{0}$ state, the energy barrier for the $\mathrm{N}-\mathrm{H}^{\text {cis }}$ dissociation (structure G3-[3] $]^{\S}$ ) is $\Delta E^{\neq}=378 \mathrm{~kJ} \mathrm{~mol}^{-1}$ (Fig. 3c). For the $\mathrm{N}-\mathrm{H}^{\text {trans }}$ dissociation, the $\mathrm{S}_{1}$ potential energy curve with constrained $\mathrm{O}-\mathrm{H}$ distance reveals a maximum at $R_{\mathrm{N}-\mathrm{H}(3)}=1.30$ $\AA$ (structure E4-[2]*) and $\Delta E^{\mathrm{Rel}}=-43 \mathrm{~kJ} \mathrm{~mol}^{-1}$, yielding structure E4-[3] $]^{\S}$ with $R_{\mathrm{N}-\mathrm{H}(3)}=1.55 \AA$. Similar to the case of the $\mathrm{N}-\mathrm{O}$ dissociation, CASPT2 $(10,9)$ geometry optimizations confirmed that E3-[2]* and E4-[2]* are the transition structures for the $\mathrm{N}-\mathrm{H}(2)$ and $\mathrm{N}-\mathrm{H}(3)$ dissociation pathways, respectively, with threshold $\mathrm{N}-\mathrm{H}$ distances of 1.20 and $1.30 \AA$.

In the $\mathrm{N}-\mathrm{H}^{c i s}$ dissociation pathway, the $\mathrm{S}_{0}$ and $\mathrm{S}_{1}$ potential energy curves suggest the possibility to circumvent the $\mathrm{O}-\mathrm{H}$ dissociation pathway shown in Fig. $4 \mathrm{~b}$ by thermal excitation of structure G1-[1] to precursor structure G3-[2] $]^{\neq}$in the $\mathrm{S}_{0}$ state: at $1200 \mathrm{~K}, \Delta G^{\neq}=217 \mathrm{~kJ} \mathrm{~mol}^{-1}$ and $k^{\mathrm{Q}-\mathrm{vib}}=8.54 \times 10^{3} \mathrm{~s}^{-1}$ (Table S8†). Then, structure G3-[2 $]^{\neq}$is vertically excited to E3-[2]* with $E^{\mathrm{Ex}}=2.34 \mathrm{eV}(530 \mathrm{~nm})$, and subsequently relaxes into groundstate $\mathrm{NHOH}$ and $\mathrm{H}$ (structure $\mathbf{E 3}-[3]^{\S}$ ): at $1200 \mathrm{~K}, \Delta G^{\text {Rel }}=$ $-63 \mathrm{~kJ} \mathrm{~mol}^{-1}$ (Table S9 $\dagger$ ). In the $\mathrm{N}-\mathrm{H}^{\text {trans }}$ dissociation pathway (Fig. 4b), structure G1-[1] could be thermally excited to structure G4- $[2]^{\neq}$with $\Delta G^{\neq}=286 \mathrm{~kJ} \mathrm{~mol}^{-1}$ and $k^{\mathrm{Q}-\text { vib }}=8.82 \times 10^{0} \mathrm{~s}^{-1}$ (Table $\mathrm{S} 8 \dagger$ ), and the $\mathrm{S}_{0} \rightarrow \mathrm{S}_{1}$ vertical excitation with $E^{\mathrm{Ex}}=$ $1.92 \mathrm{eV}(646 \mathrm{~nm}$ ) leads to structure E4-[2]* and subsequently to ground-state $\mathrm{NHOH}$ and $\mathrm{H}$ (structure E4- $[3]^{\S}$ ). Because the $\Delta G^{\neq}$ for the formation of the precursor in the $S_{0}$ state (structure G4$\left.[2]^{\neq}\right)$is rather high even at the highest temperature $(1200 \mathrm{~K})$, the $\mathrm{N}-\mathrm{H}^{\text {trans }}$ dissociation is thermodynamically unfavorable. Therefore, the $\mathrm{N}-\mathrm{H}^{c i s}$ dissociation pathway is preferred, and structure $\mathbf{E 3}-[\mathbf{3}]^{\S}$ can be hypothesized as a precursor for the isomerization-dissociation of channels (6) and (7).

Analysis of the main electronic states of the characteristic structures on the potential energy curves (Tables S3 and S4 $\dagger$ ) for $\mathrm{N}-\mathrm{H}$ dissociation shows trends of the CI coefficients similar to the case of $\mathrm{O}-\mathrm{H}$ dissociation. For $\mathrm{N}-\mathrm{H}^{\text {cis }}$ dissociation, the electronic ground state $\Psi_{0}$ dominates $\left(\mathrm{C}_{0}=0.9807\right)$ the $\mathrm{S}_{0}$ state, whereas the singly excited $\Psi_{\overline{9}}^{\overline{10}}$ state $\left(\mathrm{C}_{\overline{9}}^{\overline{10}}=0.9733\right)$ dominates the $\mathrm{S}_{1}$ state. As the $\mathrm{N}-\mathrm{H}(2)$ distance increases to $R_{\mathrm{N}-\mathrm{H}(2)}=1.20 \AA$, the electronic states associated with excitations of an electron from the HOMO-1 $\left(n_{\text {orb }}=8\right)$ to the LUMO $\left(n_{\text {orb }}=10\right)$, $\Psi_{\overline{8}}^{\overline{10}}\left(\mathrm{C}_{\overline{8}}^{\overline{10}}=0.0641\right)$ and $\Psi_{9, \overline{8}}^{10, \overline{10}}\left(\mathrm{C}_{9, \overline{8}}^{10, \overline{10}}=0.0843\right)$, appear in the $\mathrm{S}_{0}$ and $\mathrm{S}_{1}$ states, respectively. Their respective maximum, $\mathrm{C}_{\overline{8}}^{\overline{10}}=0.1943$ and $\mathrm{C}_{9, \overline{8}}^{10, \overline{10}}=0.2240$, is observed at the intersection of the $S_{0}$ and $S_{1}$ states, corresponding to dissociated $\mathrm{N}-$ $\mathrm{H}(2)$. Therefore, E3-[2] $]^{\neq}$and $R_{\mathrm{N}-\mathrm{H}}=1.20 \AA$ are confirmed to be the transition structure and the threshold $\mathrm{N}-\mathrm{H}(2)$ distance for the evolution of the Rydberg orbitals, respectively.

\section{$\mathrm{NH}_{3} \mathrm{O}$ formation}

The relaxed $S_{1}$ potential energy scan suggests that, starting from the O-H dissociated E1-[3] $]^{\S}$ structure, $\mathrm{H}(5) \rightarrow \mathrm{N}$ unimolecular isomerization occurs at $R_{\mathrm{N}-\mathrm{H}(5)}=1.85 \AA$ (structure E5-[1] in Fig. 5a). The results of ref. 11 showed that, in the $S_{0}$ state, the one-step $\mathrm{H}(5) \rightarrow \mathrm{N}$ unimolecular isomerization has a high energy barrier $\left(\sim 234 \mathrm{~kJ} \mathrm{~mol}^{-1}\right)$. In contrast, we found that the formation of $\mathrm{NH}_{3} \mathrm{O}$ from the $\mathrm{O}-\mathrm{H}$ dissociated structure is barrierless and spontaneous in the $\mathrm{S}_{0}$ state $\left(\Delta G^{\mathrm{Rel}}=-205 \mathrm{~kJ} \mathrm{~mol}^{-1}\right.$ at $1200 \mathrm{~K}$, Table $\mathrm{S} 10^{\dagger}$ ), and mediated by transition structure E5$[2]^{\neq}\left(\Delta G^{\neq}=81 \mathrm{~kJ} \mathrm{~mol}^{-1}\right.$ and $k^{\mathrm{Q}-\mathrm{vib}}=7.55 \times 10^{9} \mathrm{~s}^{-1}$, Table S11 $\left.\dagger\right)$ in the $S_{1}$ state. Because the total energies of structures E1-[3] $]^{\S}$ and G5-[1] are similar (Fig. 6a), the two-step pathway involving E1- $[3]^{\S}$ as the precursor is the preferred mechanism. 
The CI coefficients listed in Table $\mathrm{S} 5 \dagger$ reveal that, in the $\mathrm{S}_{0}$ state, the potential energy curve for the $\mathrm{H}(5) \rightarrow \mathrm{N}$ isomerization is purely repulsive because of an increase in the contribution of the electronic ground state, $\Psi_{0}: \mathrm{C}_{0}=0.6747,0.9514$, and 0.9715 for structures G5-[1] $]^{\S}$, G5-[2], and G5-[3], respectively. The increase in $\mathrm{C}_{0}$ is accompanied by a significant decrease in the contribution of excitations from the HOMO-1. As an example, $\mathrm{C}_{\overline{8}}^{\overline{10}}=0.6018, \mathrm{C}_{\overline{8}}^{\overline{11}}=0.1352$, and $\mathrm{C}_{\overline{8}}^{\overline{11}}=0.0783$ for $\mathbf{G 5}-[1]^{\S}$, G5[2], and G5-[3], respectively. In the $S_{1}$ state, the formation of $\mathrm{NH}_{3} \mathrm{O}$ is associated to an increasing energy because of an increase in the contributions of the singly excited $\Psi_{\overline{9}}^{\overline{10}}$ configuration: $\mathrm{C}_{\overline{9}}^{\overline{10}}=0.9306,0.9525$, and 0.9711 for structures E5$[1], \mathbf{E 5}-[2]^{\neq}$, and E5-[3], respectively.

\section{HNO and $\mathrm{H}_{2}$ formation}

Intuitively, two precursors are possible for isomerization in channel (6), E1-[3] $]^{\S}$ and $\mathbf{E} 3-[3]^{\S}$, i.e., the $\mathrm{O}-\mathrm{H}(5)$ and $\mathrm{N}-\mathrm{H}(2)$ dissociated structure, respectively. Starting from either structure and using $R_{\mathrm{H}(2)-\mathrm{H}(5)}=1.50 \AA, \mathrm{H}(5) \rightarrow \mathrm{H}(2)$ isomerization readily occurs at the intersection of the $S_{0}$ and $S_{1}$ states, yielding structure E6-[1] $]^{\S}$, as shown in Fig. 5 b. This suggests that $\mathrm{O}-\mathrm{H}$ dissociation occurs first. The potential energy curves for the $\mathrm{H}(5) \rightarrow \mathrm{H}(2)$ isomerization show two possibilities for the formation of $\mathrm{HNO}$ and $\mathrm{H}_{2}$, which are structures E6-[3] and G6[3] in the $S_{1}$ and $S_{0}$ state, respectively. In the $S_{1}$ state, E6-[3] can form with a low free energy barrier via transition structure E6$[2]^{\neq}\left(\Delta G^{\neq}=12 \mathrm{~kJ} \mathrm{~mol}^{-1}, k^{\mathrm{Q}-\mathrm{vib}}=7.78 \times 10^{12} \mathrm{~s}^{-1}\right.$, and $\Delta G^{\mathrm{Rel}}=$ $-328 \mathrm{~kJ} \mathrm{~mol}^{-1}$ at $1200 \mathrm{~K}$, Table S11 $\dagger$ ). The existence of E6-[3] as an equilibrium structure in the $S_{1}$ state supports the experimental finding that the reactive HNO radical has a rather long lifetime $(0.1 \mathrm{~s})$ and is one of the dominant products in the gasphase isolated system. ${ }^{18}$

In contrast, the formation of $\mathrm{HNO}$ and $\mathrm{H}_{2}$ from structure G6$[1]^{\S}$ is barrierless and spontaneous $\left(\Delta G^{\mathrm{Rel}}=-363 \mathrm{~kJ} \mathrm{~mol}^{-1}\right.$, Table S10 $\left.\dagger^{\dagger}\right)$ in the $\mathrm{S}_{0}$ state, with structure G6-[3] $\left(E^{\mathrm{Ex}}=1.40 \mathrm{eV}\right.$, corresponding to $886 \mathrm{~nm}$ ) as the product. The value of $E^{\mathrm{Ex}}$ is in excellent agreement with the threshold wavelength associated with the formation of $\mathrm{HNO}$ and $\mathrm{H}_{2}, \lambda_{\text {thres }}=891 \mathrm{~nm}(1.39 \mathrm{eV})$, which was obtained experimentally from the excitation of $\mathrm{NH}_{2} \mathrm{OH}$ by UV photons at $193 \mathrm{~nm}$ and thermodynamic data. ${ }^{5}$ The $\mathrm{H}(5) \rightarrow \mathrm{H}(2)$ unimolecular isomerization-dissociation mechanisms of the $S_{0}$ and $S_{1}$ states are depicted in Fig. $6 b$.

The electronic states reported in Table $\mathrm{S} 6 \dagger$ suggest a trend of the CI coefficients for $\mathrm{HNO}$ and $\mathrm{H}_{2}$ formation similar to that of $\mathrm{NH}_{3} \mathrm{O}$ formation. In the $\mathrm{S}_{0}$ state, the reaction is spontaneous because of the increased contributions of $\Psi_{0}$ along the potential energy curve $\left(\mathrm{C}_{0}=0.9141,0.9212\right.$, and 0.9493 for structures G6[1], G6-[2], and G6-[3], respectively). In the $S_{1}$ state, the contribution of $\Psi_{\overline{9}}^{\overline{10}}$ increases along the $\mathrm{S}_{1}$ potential energy curve $\left(\mathrm{C}_{\overline{9}}^{\overline{10}}=0.9086,0.9270\right.$, and 0.9557 , respectively $)$.

\section{NH and $\mathrm{H}_{2} \mathrm{O}$ formation}

Similar to the $\mathrm{HNO}$ and $\mathrm{H}_{2}$ case, the potential energy curves for $\mathrm{H}(2) \rightarrow \mathrm{O}$ isomerization shown in Fig. $5 \mathrm{c}$ evidence the existence of two possibilities for the formation of $\mathrm{NH}$ and $\mathrm{H}_{2} \mathrm{O}$. Starting from the $\mathrm{N}-\mathrm{H}^{c i s}$ dissociated structure (structure $\mathbf{E 3}-[3]^{\S}$ ), the
$\mathrm{H}(2) \rightarrow \mathrm{O}$ isomerization occurs instantaneously in the $\mathrm{S}_{1}$ state (structure E7-[1], $R_{\mathrm{O}-\mathrm{H}(2)}=1.80 \AA$ ). As the $\mathrm{O}-\mathrm{H}(2)$ distance decreases, the $\mathrm{S}_{0}$ and $\mathrm{S}_{1}$ potential energy curves converge to $R_{\mathrm{O}-}$ $\mathrm{H}(2)=1.30 \AA$ and reach their minimum at $R_{\mathrm{O}-\mathrm{H}(2)}=0.97 \AA$ (structure $\mathbf{G 7 - [ 3 ] ) ; ~ a t ~} 1200 \mathrm{~K}, \Delta G^{\mathrm{Rel}}$ in the $\mathrm{S}_{1}$ state is $-319 \mathrm{~kJ} \mathrm{~mol}^{-1}$ (Table S11 $\dagger$ ). The situation is the same in the $\mathrm{S}_{0}$ state, in which structure G7-[1] spontaneously turns into structure G7-[3]; at $1200 \mathrm{~K}, \Delta G^{\mathrm{Rel}}=-152 \mathrm{~kJ} \mathrm{~mol}^{-1}$ (Table S10 $\dagger$ ). Because the total energies of structures E3-[3] $]^{\S}$ and G7-[1] are closer than structures E3-[3] $]^{\S}$ and E7-[1], the H(2) $\rightarrow$ O unimolecular isomerization-dissociation preferentially occurs in the $\mathrm{S}_{0}$ state (Fig. $6 \mathrm{c}$ ).

For $\mathrm{H}(2) \rightarrow \mathrm{O}$ isomerization, the CI coefficients listed in Table $\mathrm{S} 7 \dagger$ show the same multiconfigurational character along the potential energy curves of the $\mathrm{H}(5) \rightarrow \mathrm{N}$ and $\mathrm{H}(2) \rightarrow \mathrm{H}(5)$ isomerization. In the $\mathrm{S}_{0}$ state, the contribution of the electronic ground state increases whereas the contribution of the singly excited state increases in the $S_{1}$ state.

\section{The interplay between thermal excitations and photoexcitations}

The previous sections show in detail the relative Gibbs free energies of the elementary processes and the effects of electronic configuration changes on the potential energy curves. To describe completely the role played by thermal energy in photolytic mechanisms, especially investigating the heat exchange in the endothermic and exothermic processes, the enthalpy changes $(\Delta H)$ were calculated in the elementary steps. For the direct photolysis of the $\mathrm{N}-\mathrm{O}$ and $\mathrm{N}-\mathrm{H}$ covalent bonds, which involves the formation of the precursors in the $\mathrm{S}_{0}$ state, the linear relationship between $\ln k^{\mathrm{Q}-\mathrm{vib}}(T)$ and $1 / T$ of eqn (9) was used. For the spontaneous isomerization in the $\mathrm{S}_{0}$ state (channels (5)-(7), negative $\Delta G^{\mathrm{Rel}}$ ), the conventional Gibbs free energy change $\left(\Delta G^{\mathrm{Rel}}=\Delta H^{\mathrm{Rel}}-T \Delta S^{\mathrm{Rel}}\right)$ was used to approximate the enthalpies of the exothermic processes $\left(\Delta H^{\mathrm{Rel}}\right)$. Fig. S2a $\uparrow$ shows that the linear relationship between $\ln k^{\mathrm{Q}-\mathrm{vib}}(T)$ and $1 / T$ is maintained over the entire temperature range. The values of $\Delta H^{\neq}$in Table S8† evidence that, for the $\mathrm{N}-\mathrm{O}$ and $\mathrm{N}-$ $\mathrm{H}^{\text {cis }}$ dissociation, the thermal energies required for the formation of the precursors in the $S_{0}$ state are similar to those required for the formation of the Rydberg orbital (structure G1$[2]^{\neq}$), being $\Delta H^{\neq}=190,208$ and $199 \mathrm{~kJ} \mathrm{~mol}^{-1}$ with $k^{\mathrm{Q}-\mathrm{vib}}(T)=$ $7.75 \times 10^{4}, 8.54 \times 10^{3} \mathrm{~s}^{-1}$ and $1.82 \times 10^{4}$, respectively.

For the barrierless, direct covalent bond dissociations in the $\mathrm{S}_{1}$ state, the relationship between $\Delta G^{\mathrm{Rel}}$ and $T$ is linear over the entire temperature range (Fig. $\mathrm{S} 2 \mathrm{~b} \dagger$ ). Table $\mathrm{S} 9 \dagger$ reveals that the heat release related to $\mathrm{O}-\mathrm{H}$ and $\mathrm{N}-\mathrm{H}$ dissociation in the $\mathrm{S}_{1}$ state is not substantial, compared with that of $\mathrm{N}-\mathrm{O}$ dissociation $\left(\Delta H^{\mathrm{Rel}}=-3,-9\right.$ and $-124 \mathrm{~kJ} \mathrm{~mol}^{-1}$, respectively). Additionally, the exothermic energies of isomerization-dissociation in the $\mathrm{S}_{0}$ state (Table S10 $\dagger$ ) exceed the thermal energy required for the formation of the precursors, $\Delta H^{\mathrm{Rel}}=-219$ and $-279 \mathrm{~kJ} \mathrm{~mol}^{-1}$ for channels (5) and (6), respectively. Assuming that the thermal energies generated in the exothermic processes can be transferred to other $\mathrm{NH}_{2} \mathrm{OH}$ molecules, the exothermic isomerization-dissociation of channel (6), which generates $\mathrm{HNO}$ and $\mathrm{H}_{2}$, 
could generate a relevant excess thermal energy for the formation of the precursors in the $S_{0}$ state. Thus, the source of thermal energy required to generate the precursors in the $S_{0}$ state is the formation of $\mathrm{HNO}$ and $\mathrm{H}_{2}$. This is supported by the finding that the formation of $\mathrm{HNO}$ and $\mathrm{H}_{2}$ is the preferred process in UV experiments at $193 \mathrm{~nm}$, and that $\mathrm{HNO}$ is a dominant product in the gas-phase isolated system. ${ }^{18}$

\section{Conclusion}

The photodissociation mechanisms of $\mathrm{NH}_{2} \mathrm{OH}$ in the lowest singlet-excited state were studied by ab initio calculations in the CASPT2(10,9)/aug-cc-pVDZ framework. This study focused on nonradiative relaxation processes that convert the excited-state molecule to its electronic-ground-state products and on the role played by thermal excitation in photodissociation. All the important equilibrium structures in the $S_{0}$ and $S_{1}$ states were characterized, and the potential energy curves for direct covalent bond dissociation and unimolecular isomerization-dissociation were calculated. Additionally, thermodynamic and kinetic data associated with the elementary processes were extracted using the transition state theory.

The CASPT2 $(10,9)$ geometry optimizations showed that, in the $\mathrm{S}_{0}$ state, the $\mathrm{NH}_{2} \mathrm{OH}$ equilibrium structure is a 3-D structure with $C_{\mathrm{S}}$ symmetry. An $\mathrm{S}_{0} \rightarrow \mathrm{S}_{1}$ vertical excitation energy of $6.38 \mathrm{eV}(194 \mathrm{~nm})$ was calculated, and $\mathrm{NH}_{3} \mathrm{O}, \mathrm{HNO}$, and the $\mathrm{NH}-$ $\mathrm{H}_{2} \mathrm{O}$ complex were found to be stable in the $\mathrm{S}_{0}$ and $\mathrm{S}_{1}$ states. Analysis of the CI coefficients of the equilibrium structures revealed that the interference of the primary electronic states with higher excited states is important and that the multiconfigurational character of these structures must be included in $a b$ initio studies. Because all the equilibrium structures and energetics are in good agreement with the available theoretical and experimental data, the use of the CASPT2 $(10,9)$ method was proved to be appropriate.

The potential energy curves obtained from the CASPT2 $(10,9)$ and relaxed scan methods confirmed that $\mathrm{O}-\mathrm{H}$ dissociation dominates in the $\mathrm{S}_{1}$ state. Analysis of the CI coefficients of the characteristic structures on the potential energy curves revealed changes in the multiconfigurational character of the pathway upon O-H dissociation. For example, at the inflection point $\left(R_{\mathrm{O}-}\right.$ $\mathrm{H}(5)=1.15 \AA)$ of the $S_{1}$ potential energy curve $\left(\Psi_{\overline{9}}^{\overline{10}}\right)$, an electronic state associated with excitation of an electron from the lone-pair orbital of the $\mathrm{O}$ atom to the Rydberg orbital $\left(\Psi_{9, \overline{8}}^{10, \overline{10}}\right)$ emerges, having its maximum at the intersection of the $S_{0}$ and $\mathrm{S}_{1}$ states. Therefore, the structure at the inflection point is considered a transition structure, and $R_{\mathrm{O}-\mathrm{H}(5)}=1.15 \AA$ is considered to be the threshold distance for the development of Rydberg orbitals, which separates the bound and dissociated electronic states (bound-free transition). These conclusions were used as guidelines to discuss the other photodissociation processes.

Because $\mathrm{O}-\mathrm{H}$ dissociation is the preferred process in the $\mathrm{S}_{1}$ state, the $\mathrm{S}_{1}$ potential energy curves for the $\mathrm{N}-\mathrm{O}$ and $\mathrm{N}-\mathrm{H}$ dissociations were initially constructed by constraining the $\mathrm{O}-\mathrm{H}$ distance to its equilibrium $\mathrm{S}_{0}$ value. To prevent $\mathrm{O}-\mathrm{H}$ dissociation, the equilibrium structure in the $S_{0}$ state must be thermally excited to form appropriate precursors, as suggested by the potential energy curves. Then, the thermally excited precursors are vertically excited to form the transition structures in the $S_{1}$ state, which then relax nonradiatively along purely repulsive potential energy curves to generate the products in their respective electronic ground states. Although the required thermal energies are relatively high, according to our thermodynamic and kinetic results, the exothermic energy related to the formation of $\mathrm{HNO}$ and $\mathrm{H}_{2}$ is at least equally high. Therefore, the thermal excitations in the $\mathrm{S}_{0}$ state determine the rate of $\mathrm{N}-\mathrm{O}$ and $\mathrm{N}-\mathrm{H}$ dissociation. The proposed mechanisms, which involve different thermally excited precursors, are supported by experimental observations that show that different photon energies lead to different products in their electronic ground state.

The potential energy curves and thermodynamic results revealed that the unimolecular isomerization-dissociation effectively generates products in their electronic ground state through the direct photolysis of the corresponding covalent bonds. In particular, for the formation of $\mathrm{HNO}$ and $\mathrm{H}_{2}$, the potential energy curves suggested that the high quantum yield of photolysis by UV absorption at $193 \mathrm{~nm}$ results from a twostep process: first, the $\mathrm{O}-\mathrm{H}$ bond dissociates; then, isomerization and the formation of $\mathrm{H}_{2}$ in its electronic ground state on a purely repulsive potential curve occur through a strong exothermic process. Overall, the mechanisms proposed in this work emphasize the roles of thermal selectivity and the multiconfigurational character of the associated wavefunctions. Because detailed information on these aspects is limited both theoretically and experimentally, this work provides important insights into the photodissociation of $\mathrm{NH}_{2} \mathrm{OH}$. Thus, it can be ground for future theoretical and experimental studies of similar systems.

\section{Conflicts of interest}

There are no conflicts to declare.

\section{Acknowledgements}

Prof. Kritsana Sagarik would like to acknowledge the financial support provided by SUT Research and Development Fund, Project Number: IRD1-102-59-12-13. The financial support provided by the Thailand Research Fund (TRF) (Grant No. MRG6180120) to Dr Jittima Thisuwan is also gratefully acknowledged.

\section{References}

1 J. H. Seinfeld and S. N. Pandis, Atmospheric Chemistry and Physics: From Air Pollution to Climate Change, John Wiley \& Sons, Inc., Hoboken, New Jersey, 3rd edn, 2016.

2 J. Baker, V. Butcher, J. M. Dyke and A. Morris, J. Chem. Soc., Faraday Trans., 1990, 86, 3843-3851.

3 J. Betts and R. A. Back, Can. J. Chem., 1965, 43, 2678-2684.

4 L. A. Curtiss, J. Chem. Phys., 1982, 77, 3605. 
5 K.-H. Gericke, M. Lock, F. Schmidt and F. J. Comes, J. Chem. Phys., 1994, 101, 1988-1995.

6 K. Kimura and S. Katsumata, J. Chem. Phys., 1977, 67, 12251230.

7 D. Luckhaus, J. L. Scott and F. F. Crim, J. Chem. Phys., 1999, 110, 1533-1541.

8 U. Bozkaya, J. M. Turney, Y. Yamaguchi and H. F. Shaefer III, J. Chem. Phys., 2012, 136, 164303.

9 I. I.-Burmazović, in The Chemistry and Biology of Nitroxyl (HNO), ed. F. Doctorovich, P. J. Farmer and M. A. Marti, Elsevier, 2017, ch. 5, pp. 67-104.

10 M. Ren, B. Dong and W. Lin, in The Chemistry and Biology of Nitroxyl (HNO), ed. F. Doctorovich, P. J. Farmer and M. A. Marti, Elsevier, 2017, ch. 10, pp. 207-224.

11 R. D. Bach, A. L. Owensby, C. Gonzalez, H. B. Schlegel and J. J. W. McDouall, J. Am. Chem. Soc., 1991, 113, 6001-6011.

12 M. Brönstrup, D. Schröder, I. Kretzschmar, C. A. Schalley and H. Schwarz, Eur. J. Inorg. Chem., 1998, 1529-1538.

13 A. J. Kirby, J. E. Davies, D. J. Fox, D. R. W. Hodgson, A. E. Goeta, M. F. Lima, J. P. Priebe, J. A. Santaballa and F. Nome, Chem. Commun., 2010, 46, 1302-1304.

14 C. Trindle and D. D. Shillady, J. Am. Chem. Soc., 1973, 95, 703-707.

15 V. Staemmler, Acta Phys. Pol., A, 1988, 74, 331.

16 J. A. Miller and C. T. Bowman, Prog. Energy Combust. Sci., 1989, 15, 287-338.

17 B. L. Ulich, J. M. Hollis and L. E. Snyder, Astrophys. J., 1977, 217, L105-L108.

18 F. W. Dalby, Can. J. Phys., 1958, 36, 1336-1371.

19 Y. Zhang, J. Inorg. Biochem., 2013, 118, 191-200.

20 M. D. Bartberger, J. M. Fukuto and K. N. Houk, Proc. Natl. Acad. Sci. U. S. A., 2001, 98, 2194-2198.

21 P. Hänggi, P. Talkner and M. Borkovec, Rev. Mod. Phys., 1990, 62, 251.

22 E. Pollak and P. Talkner, Chaos, 2005, 15, 026116.

23 L. González, D. Escudero and L. S.-Andrés, ChemPhysChem, 2012, 13, 28-51.
24 M. Schreiber, M. R. S.-Junior, S. P. A. Sauer and W. Thiel, J. Chem. Phys., 2008, 128, 134110.

25 P. Suwannakham, S. Chaiwongwattana and K. Sagarik, RSC Adv. , 2018, 8, 36731-36744.

26 H. Hettema and D. R. Yarkony, J. Chem. Phys., 1995, 102, 8431-8439.

27 H.-J. Werner, P. J. Knowles, G. Knizia, F. R. Manby and M. Schütz, Wiley Interdiscip. Rev.: Comput. Mol. Sci., 2012, 2, 242-253.

28 H.-J. Werner, P. J. Knowles, G. Knizia, F. R. Manby, M. Schütz and others, MOLPRO (version 2015.1, a package of ab initio programs), TTI GmbH, Stuttgart, 2015.

29 P. J. Knowles and H.-J. Werner, Chem. Phys. Lett., 1985, 115, 259-267.

30 H.-J. Werner and P. J. Knowles, J. Chem. Phys., 1985, 82, 5053-5063.

31 H.-J. Werner and W. Meyer, J. Chem. Phys., 1980, 73, 23422356.

32 J. Q. Sun and K. Ruedenberg, J. Chem. Phys., 1994, 101, 2157. 33 D. S. Sholl and J. A. Steckel, Density Functional Theory: A Practical Introduction, John Wiley \& Sons, Inc., Hoboken, New Jersey, 2009.

34 J. E. House, Principles of Chemical Kinetics, Elsevier, USA, 2nd edn, 2007.

35 E. Wigner, Z. Phys. Chem., 1932, 15, 203-216.

36 E. Wigner, Trans. Faraday Soc., 1938, 34, 29-41.

37 J. Kästner, J. M. Carr, T. W. Keal, W. Thiel, A. Wander and P. Sherwood, J. Phys. Chem. A, 2009, 113, 11856-11865.

38 ChemShell, a Computational Chemistry Shell, see http:// www.chemshell.org.

39 A. G.-Espinoza, J. H.-Cobos and I. O.-Blake, J. Chem. Phys., 2011, 135, 054502.

40 S. Tsunekawa, J. Phys. Soc. Jpn., 1972, 33, 167-174.

41 X. Luo, P. R. Fleming, T. A. Seckel and T. R. Rizzo, J. Chem. Phys., 1990, 93, 9194.

42 M. Suto and L. C. Lee, J. Chem. Phys., 1983, 78, 4515.

43 B. Gelernt, S. V. Filseth and T. Carrington, Chem. Phys. Lett., 1975, 36, 238. 